\title{
Rice "Instant Inoculation” With Endophytic Fungus Causes Excessive Immune Response To Fusarium Proliferatum And Plant cell Death
}

Chuan-Chao Dai ( $\nabla$ daichuanchao@njnu.edu.cn )

Nanjing Normal Univerisity https://orcid.org/0000-0002-0980-0018

Qiang Zhu

Nanjing Normal Univerisity

Man Chen

Nanjing Normal Univerisity

Fan Lu

Nanjing Normal Univerisity

Kai Sun

Nanjing Normal Univerisity

Meng-Jun Tang

Nanjing Normal Univerisity

Wei Zhang

Nanjing Normal Univerisity

Yuan-Qing Bu

Nanjing Normal Univerisity

\section{Research Article}

Keywords: Beneficial microorganism, Rice, Pre-inoculation, Induced resistance, Instant inoculation, ROS, Cell death

Posted Date: September 13th, 2021

DOl: https://doi.org/10.21203/rs.3.rs-840279/v1

License: (c) (i) This work is licensed under a Creative Commons Attribution 4.0 International License.

Read Full License 


\section{Abstract}

Aims: This article explored the effects and possible mechanism of different inoculation patterns of endophytic fungi Phomopsis liquidambaris B3 on the plant immune response and defense results to pathogen Fusarium. proliferatum.

Methods: Rice seedlings pre-inoculated, instant-inoculated and non-inoculated with B3 were infected with F. proliferatum and grown in controllable conditions. The disease severity, F. proliferatum infection and plant growth were evaluated, and the activity of defensive enzymes, defense-related substances, reactive oxygen content, and defense hormone SA content were determined. Chemical treatment experiments and plant cell staining to verify plant cell death.

Results: Pre-inoculation of endophytic fungus Ph. liquidambaris B3 may triggered the SA-dependent defense pathways of plants, increased defense-related enzyme activities and up-regulated the expression of defense genes, and thus decreased F. proliferatum colonization. However, instant-inoculation Ph. liquidambaris B3 inhibited its own root colonization, caused excessive burst of ROS and leaves cell death.

Conclusion: For a specific plant pathogen, the instant-inoculation Ph. liquidambaris B3 when $F$. proliferatum infected leads to excessive burst of reactive oxygen species (ROS) and plant cell death. We recommend pre-inoculation of biological control agent and other prevention and control measures before pathogen infection to achieve the best control effect rather than instant control method applicated in the agricultural crop management.

\section{Introduction}

In the sustainable intensification of global agricultural production, crop health and food security are constantly receiving attention. In the long history of cultivation, humans have adopted farming strategies such as crop rotation to avoid soil-borne diseases, and targeted used microorganisms to against herbivores (Finkel et al. 2017). At present, the use of beneficial microorganisms to improve crop health and alleviate and protect plants from stress has become a research hotspot (Zandi et al. 2021; Sahoo et al. 2013). Currently, the Organic Materials Review Institute (OMRI) lists 174 'microbial inoculants' products and 274 'microbial products201', as crop fertilizers or crop management tools could be applied in agriculture (Finkel et al. 2017). Surprisingly, most beneficial microorganisms are much less effective in field applications than in the laboratory due to environmental suitability, the persistence of beneficial microorganisms in the soil and other several limiting factor (Schreiter et al. 2014; Weidner et al. 2015). This inevitably raises the question of how to achieve the precise application and management of beneficial microbes to ensure and increase the control effect in consideration of different actual characteristics (for example, application time and place of beneficial microbes, local climate and soil conditions). Thus, understanding and exploring the physiological changes and immune responses of host plants colonized by beneficial microorganisms and pathogens will be critical for realizing the 
pertinence and precise application and developing the management options that maximize beneficial microorganisms for crop diseases control and save agricultural production costs.

In order to survive, plants have evolved a complex and sophisticated immune system to recognize and adapt to the attack of pathogenic microorganisms (Jones and Dangl 2006; Cui et al. 2015). When pathogens invade plants, plant cell walls are first attacked (Lee et al. 2019). Rice blast fungus

Magnaporthe grisea can successfully invade host cells by producing appressorium to penetrate the plant cell wall (Park et al. 2002). Lignin, calluses, colloids and another effective ingredient for thicking and augmenting structural barriers of pathogen invasion (Hematy et al. 2009; Luna et al. 2010). In addition, the vast commensal and mutualistic microbial communities surrounding and, in the plants, also provide related necessary services (Chen et al. 2020; Han et al. 2020). A recent study reported that the symbiotic microbe Chitinophagaceae and Flavobacteriaceae, which lives in the roots of beet seedlings, were found to be enriched in the endosphere, and the change of endophytic root microbiome constitutes a second microbiological layer of plant defense to protect plants once pathogen bypasses the first layer and invaded plants (Carrión et al. 2019). More importantly, pathogen invasion trigger defense responses, for instance, augmented production of reactive oxygen species (ROS), caused hypersensitivity reactions, and released effect factors, to rise the challenge of pathogens (Dangl et al. 2001; Mou et al. 2003; Balint et al. 2019). Plant hormones such as salicylic acid (SA), jasmonic acid (JA), ethylene (ET), and cytokinin (GA) are key signal molecules in regulate various physiological metabolic reactions in plants and participate in plant defense responses to pathogenic microorganisms (Hussain et al. 2013; De Bruyne et al. 2013; Huai et al. 2019). When pathogen successfully evade the multi-layer defenses of host plants, they can invade plants and cause diseases (Coll et al. 2011).

Studies have shown that beneficial symbiotic microorganisms can survive and reproduce in plants without causing obvious pathological effects of host plants, but assist plants in obtaining nutrients, promote plant growth, and induce plant resistance (Pieterse et al. 2014; Lugtenberg et al. 2009). The most typical representatives of these microorganisms are AM, root nodule symbioses and plant-growthpromoting bacteria (PGPR) (Peer et al. 1991; Barrio et al. 2020; Mun et al. 2020). Generally, induced resistance (IR) enhanced defensive capacity of the entire plant against a broad spectrum of pathogens (Walters et al. 2013). It is generally believed that the colonization of rhizosphere non-pathogenic or beneficial microorganisms in plant roots triggered ISR, which is mediated by JA-ET-sensitive pathway in plants, and enhances resistance to pathogen in non-induced site (Spoel and Dong 2012). SAR is triggered upon local activation of a PTI or ETI response by necrotizing pathogens or insects and predominantly mediated by SA and the accumulation of pathogenesis-related (PR) proteins (Corina et al. 2009). In fact, most immune responses in plants are highly similar or identical due to beneficial and pathogenic microbes share physiological features and an evolutionary proximity (Rodriguez et al. 2019).

Transcriptome analysis of Arabidopsis. thaliana leaves live with commensal microbes showed that these symbiotic microorganisms do activate the first layer of plant immune response. Nearly 400 genes were up-regulated in treated plants and partly overlapped with Pseudomonas syringae induced, while $A$. thaliana does not show disease symptoms (Vogel et al., 2016). Like pathogens, beneficial microorganisms also need to overcome or evade the immune response of plants in order to establish a 
long-term and intimate mutually beneficial interaction with the host. It has been reported that the colonization of PGPR in plant roots may require local suppression of PTI to prevent the production of antibacterial compounds by MAMP triggered (Wang et al. 2012; Zamioudis et al. 2012; Pieterse et al. 2014). However, how the differential time colonization of beneficial microorganisms regulates plant immune response and the underlying mechanisms upon pathogens challenge is still unclear. In particular, it is unknown whether the difference colonization time determines the winner in the race between plants and pathogens.

In this study, we explored the differences between beneficial endophytic microbes and pathogen inoculation sequence in plant immune response in order to seek the crop precise management for maximum protection of plants. A beneficial commensal fungus, Ph. Liquidambaris, namely B3, isolated from the inner bark of the stem of Bischofia polycarpa, as a root endophyte in rice with no visible infection symptoms (Chen et al. 2011). Previous studies have shown that Ph. Liquidambaris can control Rice spikelet rot disease (RSRD), and improve crop yields (Zhu et al. 2020). However, the difference of $P h$. Liquidambaris inoculation time on the growth and ability of plants to resist pathogens is still unclear. Thus, this study addresses the following questions: (a) Whether different inoculation times of Ph. Liquidambaris affect plant disease resistance (b) Whether different inoculation times of $P h$.

Liquidambaris and pathogen infection cause the difference of plant immune system response or immune pathway.

\section{Materials And Methods}

Fungal stains

Ph. liquidambaris strain B3 and the plant pathogen F. proliferatum $\mathrm{Ff}-1$ caused rice spikelet rot disease, were obtained from the Jiangsu Key Laboratory for Microbes and Functional Genomics, China. Ph. liquidambaris strain B3 was labeled with a green fluorescent protein (GFP) by the vector plasmid pCT74 and colonized in root of rice as root endophyte. Ph. liquidambaris strain B3 was stored and activated as previously described (Sun et al. 2020). Fungal hyphae were collected and washed twice with sterile distilled water and suspend again in sterile distilled water as fungal inoculum. The plant pathogen $F$. proliferatum Ff-1 was stored and activated on PDA ( $200 \mathrm{~g}^{-1}$ potato extract, $20 \mathrm{~g}^{-1}$ glucose, $\left.\mathrm{pH} 7.0\right)$ for 5 $\mathrm{d}$ at $28^{\circ} \mathrm{C}$. Add sterile distilled water and use sterile spreading rod to scrape spore suspension $\left(10^{6}\right.$ spores $\mathrm{mL}^{-1}$ ) as plant pathogen inoculants.

Plant material and growth conditions

The rice seed used was a common cultivar "Nanjing 5055" grown in Jiangsu Province, China. All rice seeds were surface disinfected with $70 \%(\mathrm{v} / \mathrm{v})$ ethyl alcohol for $5 \mathrm{~min}$, followed by $10 \%(\mathrm{v} / \mathrm{v})$ sodium hypochloride $(\mathrm{NaClO})$ for 3 min and washed with sterile distilled water (SDW) to remove excess $\mathrm{NaClO}$ and germinated in the dark at $28^{\circ} \mathrm{C}$. The 10 - day- old rice seedings were transferred to float tray $(8 / 15 \mathrm{~cm}$, diameter/height) filled with sterilized soil substrate composed by the rice soil and vermiculite (2:1) and 
mixed thoroughly. For the inoculated group $(E+)$, each rice seedling root was inoculated with $2 \mathrm{~mL}$ of the fungal inoculum by injector, and the control treatment (E-) was treated with $2 \mathrm{~mL}$ SDW.

In order to study the influence of Ph. liquidambaris B3 different inoculation time on plant immune response, experiments were carried out, containing five treatment: (a) infected with F. proliferatum $\mathrm{Ff}-1$ after inoculation with Ph. liquidambaris B3 three days (BF, B3 pre-inoculation), (b) infected with $F$. proliferatum $\mathrm{Ff}-1$ and inoculated with Ph. liquidambaris $\mathrm{B} 3$ at the same time (FB, B3 instant-inoculation), (c) infected with F. proliferatum $\mathrm{Ff}-1$ alone $(\mathrm{F}),(\mathrm{d})$ inoculated with P. liquidambaris $\mathrm{B} 3$ alone (B), (e) noninoculated control(CK). The float trays were randomly placed at a control incubator $\left(28^{\circ} \mathrm{C}\right.$ for $16-\mathrm{h}$ light and 8-h dark) with nutrient solution every $4 \mathrm{~d}$. Fresh plant was collected at 0, 2, 4, 6, $10 \mathrm{~d}$ for experiment after inoculated. In addition, pathogenicity experiments were carried out to prove that Ff- 1 can colonize and cause disease in rice seedlings (Fig. S1).

Endophytic and pathogenic colonization

Fresh leaves and roots were collected and rinsed thoroughly with SDW to extract the rice DNA using an AxyPrep Multisource Genomic DNA Miniprep Kit (Axygen Biosciences, CA, USA). Ph. liquidambaris colonization of rice root was quantified with a specific B3 ITS primer (Bf1/ Br1) set as previously described (Zhu et al. 2020). The quantitative detection of $F$. proliferatum in rice leaves was determined using specific primer (Ff1/ Fr1) as previously described (Zhu et al. 2020).

Determination of chlorophyll content

Fresh leaves were collected, and $0.1 \mathrm{~g}$ samples were immediately ground in liquid $\mathrm{N}$. Chlorophyll was extracted with $20 \mathrm{~mL} 80 \%$ acetone at $4^{\circ} \mathrm{C}$ in the dark for $24 \mathrm{~h}$. The solution was centrifuges at 12,500 gat $4^{\circ} \mathrm{C}$ for $10 \mathrm{~min}$. The supernatants were separated and analyzed for chlorophyll content, and the absorption value was measured at $645 \mathrm{~nm}$ and $663 \mathrm{~nm}$ as per Hunt et al. (2005). Each sample was amplified in triplicate in each experiment.

Defense- enzyme assay

Fresh leaves and roots were collected, and $0.1 \mathrm{~g}$ samples were immediately ground in liquid $\mathrm{N}$, and extracted with $1 \mathrm{~mL} 0.1 \mathrm{M}$ phosphate buffer solution $\left(\mathrm{pH} 7.4,8.0 \mathrm{~g} \mathrm{~L}^{-1} \mathrm{NaCl}, 0.2 \mathrm{~g} \mathrm{~L}^{-1} \mathrm{KCl}, 1.44 \mathrm{~g} \mathrm{~L}^{-1}\right.$ $\mathrm{Na}_{2} \mathrm{HPO}_{4}$, and $0.24 \mathrm{~g} \mathrm{~L}^{-1} \mathrm{KH}_{2} \mathrm{PO}_{4}$ ), and centrifuged at $12,500 \mathrm{rpm}$ at $4^{\circ} \mathrm{C}$ for $10 \mathrm{~min}$. Enzyme activities of superoxide dismutase (SOD) and polyphenol oxidase (PPO) was measured using commercial kits (Nanjing Jiancheng Bioengineering Institute, Nanjing, China) following the manufacturer's instructions. One unit of SOD activity was defined as the quantity when the inhibition rate is $50 \%$. One unit of PPO activity was defined as an absorbance change of 0.01 per minute. Enzyme activities of chitinase and $\beta$-1,3-glucanase were detected with the 3,5- dinitrosalicylic acid (DNS) method according to Sridevi et al (2008). Colloidal chitin and laminarin (Sigma-Aldrich, Missouri, USA) were used as the substrates in

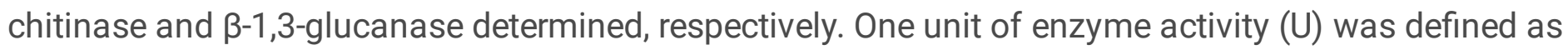


the amount of reducing sugar released per hour from chitinase and $\beta-1,3$-glucanase. Each sample was amplified in triplicate in each experiment.

Defense-related substance assay

The total phenol content in rice plants was determined using the Folin-phenol method (Zhao et al. 2016). Fresh plant samples were fully grinded and extracted in $90 \%$ ethanol solution and filled $25 \mathrm{~mL}$ to volume. $2 \mathrm{~mL}$ ethanolic extract and $2 \mathrm{~mL}$ foline-phenol solution were added in $10 \mathrm{~mL}$ centrifuge tube, then add 2 $\mathrm{mL} 10 \% \mathrm{Na}_{2} \mathrm{CO}_{3}$ within $3 \mathrm{~min}$ and mix thoroughly in the dark for $1 \mathrm{~h}$ for detected at $700 \mathrm{~nm}$. The control was determined with distilled water as extract solution. Each sample was amplified in triplicate in each experiment.

$\mathrm{H}_{2} \mathrm{O}_{2}$ and $\mathrm{NO}$ assay

Fresh rice tissues $(0.1 \mathrm{~g})$ were immediately ground in liquid $\mathrm{N}$, and extracted with $0.9 \mathrm{~mL} 0.1 \mathrm{M}$ phosphate buffer solution and centrifuged at $12500 \mathrm{rpm}$ at $4^{\circ} \mathrm{C}$ for $10 \mathrm{~min}$. The $\mathrm{H}_{2} \mathrm{O}_{2}$ and $\mathrm{NO}$ contents were measured with assay kit (Nanjing Jiancheng Bio-engineering Institute, Nanjing, China), respectively.

Histochemical marker staining assay

Trypan blue dye and Evans blue staining was used to observe plant cell death according to Morcillo et al. (2019) described, with some modification. In brief, fresh plant leaf tissues were collected at $5 \mathrm{~d}$ after $F$. proliferatum infection and placed into $5 \mathrm{~mL}$ centrifuge tubes containing trypan blue or evans blue and boiled for $3 \mathrm{~min}$, then stained at room temperature for $2 \mathrm{~h}$ for leaves. The leaves were treated with $95 \%$ ethanol until they were completely colorless.

The detection of $\mathrm{O}_{2}{ }^{--}$by NBT staining and DAB staining for $\mathrm{H}_{2} \mathrm{O}_{2}$ was performed as described by Wohlgemuth et al. (2002) and Bindschedler et al. (2006). In brief, fresh rice leaves were collected at 5 days after $F$. proliferatum infection and placed in $0.5 \mathrm{mg} \mathrm{mL}^{-1} \mathrm{NBT}$ or $1 \mathrm{mg} \mathrm{mL}^{-1} \mathrm{DAB}$ staining at $37^{\circ} \mathrm{C}$ for $2 \mathrm{~h}$ in darkness. Then the samples boil in a water bath for $10 \mathrm{~min}$ and treat with $95 \%$ ethanol until the leaves were completely colorless.

Quantification of plant hormone SA

At $0,2,4,10 \mathrm{~d}$ after treated, the leaves and roots of plant were samples for SA content determined according to Yuan et al. (2016). Briefly, $0.1 \mathrm{~g}$ samples were immediately ground in liquid $\mathrm{N}$, and added 0.5 $\mathrm{mL}$ methyl alcohol vortex shocked for $1 \mathrm{~min}$ followed by ultrasonicated for $5 \mathrm{~min}$ and extracted at $4^{\circ} \mathrm{C}$ for $24 \mathrm{~h}$. The methyl alcohol extracted was centrifugated at $14,000 \mathrm{rpm}$ for $10 \mathrm{~min}$ at $4^{\circ} \mathrm{C}$ and the precipitation was resuspension by methyl alcohol. The methyl alcohol supernatant was collected after twice centrifugation and then $10 \mu \mathrm{L}$ of $0.2 \mathrm{M} \mathrm{NaOH}$ was added followed by quickly rot-evaporate to remove methyl alcohol. Resuspend the precipitate with $250 \mu \mathrm{L} 5 \%$ trichloroacetic acid and added $0.8 \mathrm{~mL}$ of ethyl acetate: cyclohexane $(1: 1, \mathrm{v} / \mathrm{v})$. Collected the supernatants after extract twice and added $60 \mu \mathrm{L}$ 
$0.2 \mathrm{M} \mathrm{NaAc}(\mathrm{pH} 5.5)$ followed by quickly rot-evaporate, and dissolve the residue by $600 \mu \mathrm{L}$ of methyl alcohol for detection.

The SA concentration was determined using HPLC (Agilent Technology, Germany) after extraction, purification, and filtration $(0.22 \mu \mathrm{m})$ according to our previous method (Wang et al. 2011).

Chromatographic conditions: Agilent C18 column $(250 \times 4.6 \mathrm{~mm}, 5 \mu \mathrm{m})$; mobile phase: methanol: $2 \%$ acetic acid water: distilled water (50:40:10, v/v/v), the injection volume $20 \mu \mathrm{L}$, flow rate $0.7 \mathrm{~mL} \mathrm{~min}{ }^{-1}$, column temperature $25^{\circ} \mathrm{C}$, detection wavelength $290 \mathrm{~nm}$. The SA peak in the fresh sample was determined by comparing the retention time and area with the control standard.

RNA extraction and quantitative RT-PCR analysis

Real-time quantitative PCR (RT-qPCR) was performed to determine the expression levels of the genes of SA in plant. Plants were harvested at 0, 2, 4, $10 \mathrm{~d}$ after treated. Total RNA was extracted from plant samples using TRIzol reagent (Invitrogen, CA, USA), according to the manufacturer's recommendations. The primers used in the study are listed in Table S1.

qRT-PCR was performed using the StepOne Real-time PCR system (Applied Biosystems) with SYBR Green I fluorescent dye (Takara, Dalian, China). The qRT-PCR reactions were conducted in $20 \mu \mathrm{L}$, which included $10 \mu \mathrm{L} 2 \times$ SYBR Premix Ex Taq (Takara, Dalian, China), $0.4 \mu \mathrm{L}$ of each primer, $1 \mu \mathrm{L}$ of DNA template, and $7.6 \mu \mathrm{L} \mathrm{ddH} \mathrm{H}_{2} \mathrm{O}$. The reactive step of qPCR followed: $94^{\circ} \mathrm{C}$ for $1 \mathrm{~min}$, followed by 45 cycles of $94^{\circ} \mathrm{C}$ for $15 \mathrm{~s}$, $60^{\circ} \mathrm{C}$ for $45 \mathrm{~s}$ and $72^{\circ} \mathrm{C}$ for $30 \mathrm{~s}$. Relative expression levels for each gene were calculated by the $2^{-\Delta \Delta \mathrm{C}}$ method (Zhu et al. 2020).

Chemical treatment

The chemical treatment was performed in the 10-day-old seeding by adding $10 \mathrm{mM} \mathrm{H}_{2} \mathrm{O}_{2}, 5 \mathrm{mM} \mathrm{DMTU}$ (ROS scavenger, Hangzhou, China), or both them to rice leaves. The applied dose levels of the chemicals were referred to previous studies with some modified (Liu et al. 2015). The experiment contains 5 treatments: (1) infected with F. proliferatum $\mathrm{Ff}-1$ and inoculated with Ph. liquidambaris $\mathrm{B} 3$ at same time (FB); (2) FB and $5 \mathrm{mM} \mathrm{DMTU}(\mathrm{FB}+\mathrm{D})$; (3) infected with F. proliferatum Ff-1 and $10 \mathrm{mM} \mathrm{H}_{2} \mathrm{O}_{2}(\mathrm{~F}+\mathrm{H})$; (4) infected with $F$. proliferatum $\mathrm{Ff}-1,10 \mathrm{mM} \mathrm{H}_{2} \mathrm{O}_{2}$ and $5 \mathrm{mM} \mathrm{DMTU}(\mathrm{F}+\mathrm{H}+\mathrm{D})$; (5) infected with $F$. proliferatum Ff-1 (F). At $7 \mathrm{~d}$ after treated, the leaves were collected for further detection.

\section{Statistical analysis}

All experiments performed in the study were at least three times. All statistical analyses were performed using SPSS 18.0 (SPSS, Inc., Chicago, USA) and the final data were expressed as the mean with standard error (SE). When three or more groups were compared, a one-way ANOVA was performed followed by a Tukey's multiple-comparison test. The data were considered significantly different at $P \leq 0.05$. Graphs and images were assembled using Adobe Photoshop CS6 (CA, USA). 


\section{Results}

Pre-inoculated of Ph. Liquidambaris alleviates the disease symptoms caused by F. proliferatum infection and reduce pathogen colonization

First of all, we wondered whether and how the time of B3 inoculation affected the growth and disease development after rice plants infected $F$. proliferatum. Here, we found that the rice steam length of plants instant-inoculated B3 significantly higher than pre-inoculated, while the rice stems were slender and prone to lodging, and the leaves were chlorosis and withered quickly after $10 \mathrm{~d}$ infected with $F$. proliferatum (Fig. 1a). However, pre-inoculation with B3 alleviated abnormal growth caused by F. proliferatum infection and promoted root growth (Fig. 1b, 1d). The fresh weight and dry weight of rice plants were significantly higher than those of the FB treated with $5.65 \%$ and $12.08 \%$, respectively. However, there was no significant difference between rice instant-inoculation with B3 and rice infected with $F$. proliferatum alone ((Fig. 1f).

To determine whether the time of B3 inoculation affects pathogens and B3 colonization in host plants, we evaluated the F. proliferatum and B3 colonization concentration in rice leaves and roots (Fig. 1). Compared with $F$. proliferatum infection alone, pre-inoculation with B3 remarkedly reduced the number of pathogens in rice leaves, while no conspicuous effect in rice leaves instant-inoculation with B3 (Fig. 1g). On the contrary, we found that the amount of B3 colonization was significantly lower in rice roots instantinoculation with B3 than that in pre-inoculation with B3. In addition, F. proliferatum infection also reduced the amount of B3 colonization in rice roots (Fig. 1h).

Then we measured the chlorophyll content in rice leaves explore whether B3 colonization time affects photosynthesis and causes plant growth differences (Fig. 2). We found that pathogen infection significantly inhibited plant chlorophyll accumulation, while instant-inoculation with B3 did not alleviate this inhibition. The content of chlorophyll a and carotenoids in rice leaves instant- inoculated with B3 were significantly decreased by $19.10 \%$ and $37.93 \%$, compared with rice pre-inoculated with B3 (Fig. 2a, 2d). In addition, B3 inoculation increased the chlorophyll content in rice leaves, which may promote the photosynthesis of plants.

In conclusion, these results indicate that different inoculation time of B3 affects the growth and disease development of rice after $F$. proliferatum infection.

Different inoculation time of Ph. Liquidambaris causes opposite defense responses in rice to $F$. proliferatum

Then, to explore whether B3 inoculation time affects the immune response of plants to $F$. proliferatum infection, the accumulation of resistant substances like phenols and the activities of defense-related enzymes were measured (Fig. 3, 4). Here, compared to instant-inoculation with B3, the total phenol content in rice leaves pre-inoculation with B3 increased significantly from 0 to $4 \mathrm{~d}$ after $F$. proliferatum infection, and was higher than that instant-inoculation with B3 and F. proliferatum infection alone 
(Fig. 3a). During the experiment period, the total phenol content in the roots of all the treated rice plants decreased. However, the total phenol content in the rice roots instant-inoculation with B3 immediately decreased, while rice pre-inoculated with B3 increased temporarily at $4 \mathrm{~d}$ after $F$. proliferatum infection. In addition, the inoculation of B3 increased the total phenol content in rice root, compared with $F$. proliferatum infection alone (Fig. 3b).

The results of defense- related enzyme activities showed that pre-inoculation with B3 significantly enhanced the chitinase activity in rice leaves from 0 to $4 \mathrm{~d}$ after $F$. proliferatum infection, while the chitinase activity in rice plants instant-inoculation with B3 continued to decrease during $0-10 \mathrm{~d}$, even lower than that of plants F. proliferatum infection alone (Fig. 4a, 4b). Similarly, the $\beta-1,3-g l u c a n a s e$ activity in rice leaves pre-inoculation with B3 was significantly enhanced than plants instant-inoculation with B3 from 0 to $6 \mathrm{~d}$, but there was no significant difference from the plants $F$. proliferatum infection. However, no significant difference was found in the activities of chitinase and $\beta-1,3-g l u c a n a s e$ in rice roots between B3 inoculation time (Fig. 4c, 4d).

Ph. Liquidambaris inoculation time causes different plant hormone response level after $F$. proliferatum infection

Salicylic acid (SA) is an important plant hormone and plays a key role in the defense response against pathogen infection (Murphy et al. 2020). To investigated the behavior of SA in different time B3inoculated plants under the pressure of $F$. proliferatum, we measured SA concentrations in leaves and roots of rice (Fig. $5 a, 5 b)$. We found that $F$. proliferatum infection increased the SA concentration in rice leaves, which may activate the SA-dependent plant resistance immune pathway. However, the SA concentration in pre-inoculation with B3 rice leaves increased sharply after $F$. proliferatum infection, and reached 1.64 times at $2 \mathrm{~d}$ of rice instant-inoculation with B3. In addition, the SA concentration in rice leaves of instant-inoculation with B3 was significantly lower than F. proliferatum infection alone (Fig. 5a). Different from the leaves, the SA concentration in rice roots of instant-inoculation with B3 was significantly increased from 2 to $6 \mathrm{~d}$ (Fig. 5b). Then we evaluated the expression of the important gene OSPAL involved in SA synthesis and the OSPR1a gene related to the SA pathway in rice leaves. Compared with pre-inoculation with $\mathrm{B} 3$, after F. proliferatum infection, the expression of OSPAL2 and OSPR1a in rice leaves instant-inoculation with B3 was significantly down-regulated by 1.63 and 1.54 times, respectively (Fig. 5c, 5d).

These results indicate that B3 inoculation time affects the immune response of rice after $F$. proliferatum infection, including defense enzyme activity, accumulation of resistant substances, and plant hormones response. Instant-inoculation with B3 caused lower defense response than pre-inoculation, which imply that B3 inoculation time led to different levels of plant immune response and even different immune pathways.

Ph. Liquidambaris instant-inoculation leads to an excessive outbreak of plant ROS and abnormal cell death 
After infected by pathogen, plant reactive oxygen species (ROS) will burst out from the infected site to activate the plant immune system and inhibit the spread of the pathogen, the main form is $\mathrm{H}_{2} \mathrm{O}_{2}$ (Das et al. 2014). We observed that both pre-inoculation and instant-inoculation with $B 3$ enhanced the $\mathrm{H}_{2} \mathrm{O}_{2}$ outbreak after $F$. proliferatum infection (Fig. 6). It is worth noting that the $\mathrm{H}_{2} \mathrm{O}_{2}$ in the leaves of rice instant-inoculation with B3 increased strongly from 0 to $2 \mathrm{~d}$, which was 1.20 times and 1.39 times that of pre-inoculation B3, and was always significantly higher during the experiment period (Fig. 6a, 6b). On the contrary, this difference was not observed in rice root. In addition, the results of the expression of related genes involved in the synthesis of ROS showed that OsRboha and OsRbohb were significantly upregulated in rice leaves after $F$. proliferatum infection, which were 1.82 times and 2.29 times higher than those of pre-inoculation with B3 (Fig. 6c, 6d). Surprisingly, the enzyme activities involved in the ROS scavenging showed opposite results. During the entire experimental period, the SOD enzyme activity in rice leaves instant-inoculation with B3 was significantly lower than that in the pre-inoculated rice, the POD enzyme activity also showed similar changes (Fig. 7a, 7c). On the contrary, this phenomenon did not appear in rice roots (Fig. 7b, 7d).

These results suggest that instant-inoculation with B3 caused a large burst of ROS. Because high levels of ROS may cause cell death, then we performed histochemical staining on rice leaves (Fig. 8). The results showed that the cell death of leaves in pre-inoculation with $\mathrm{B} 3$ was significantly reduced, while deteriorated in instant-inoculation with $\mathrm{B} 3(\mathrm{Fig} .8 \mathrm{a}, 8 \mathrm{c})$. In addition, the $\mathrm{H}_{2} \mathrm{O}_{2}$ deposition in leaves of instant-inoculation with $\mathrm{B} 3$ was significantly higher than pre-inoculation with $\mathrm{B} 3$ (Fig. 8a). This seems to indicated the positive correlation between $\mathrm{H}_{2} \mathrm{O}_{2}$ and cell death in our experiments. Consistent with this, the expression of the positively regulated cell death gene $O S P D C D 5$ was significantly up-regulated in plants instant-inoculation with $\mathrm{B} 3$, while the expression of the negative-regulated gene OsMT2b was significantly up-regulated in plants pre-inoculation $\mathrm{B} 3$, compared with plants $F$. proliferatum infection alone (Fig. 8d)

Then, we use the $\mathrm{H}_{2} \mathrm{O}_{2}$ scavenger (DMTU) for further experiment (Fig. 8). The results showed that the disease in rice leaves with DMTU exogenous addition was alleviated, including reduction of $\mathrm{H}_{2} \mathrm{O}_{2}$ deposition and cell death (Fig. 8b). Compared with F. proliferatum infection alone, exogenous addition of $\mathrm{H}_{2} \mathrm{O}_{2}$ aggravated the disease and cell death in rice leaves, while disappeared in leaves added with $\mathrm{H}_{2} \mathrm{O}_{2}$ and DMTU (Fig. 8b).

Based on the above results, we speculate that rice plants pre-inoculation with B3 may activate and enhance the immune response after pathogen infection which may be closely related to the SA hormonedependent defense pathways, while instant-inoculation with B3 may cause programmed cell death (PCD) due to the excessive outbreak of ROS.

\section{Discussion}

Beneficial plant microorganisms have been recommended as biological control agents (BCAs) in agricultural production due to their safety and environmental- friendliness. However, low adaptability and 
efficiency limit their wide use, compared with traditional chemical pesticides (Berg et al. 2019). Studies have shown that different application treatments of beneficial microorganisms affect the field biological control effect. In the previous research, we found that the treatment of compound beneficial microbial agents did not increase the control effect of RSRD, while single strain showed better (Zhu et al. 2020). However, few studies focus on different application times on disease control of beneficial plant microorganisms, which may be a key point for affecting the disease control effects of BCAs in actual production. For example, Xu et al. (2017) found that the release time of endophytic Streptomyces endus OsiSh-2 led to significant differences on rice blast control. Spraying OsiSh-2 before rice blast occurrence was better with a disease index of $30.48 \%$, which is obviously lower than spraying after (59.25\%). In fact, the difference in application time may lead to the reversal of the relationship between pathogen and beneficial microorganisms, which may be an important limiting factor affecting the application effect in actual production. In this study, the "occupancy" time of beneficial microorganisms in the host plant leads to opposed defensive outcomes: (1) Pre-inoculation with B3 activates rice induced resistance, alleviated the abnormal growth and reduced the disease symptom, stimulates and enhances the plant defense ability and immune response to pathogen challenge; and (2) "instant" inoculation with B3 (that is, when suffering from pathogen infection) causes violent defense response accompany with excessive ROS outbreak, resulting in plant cell death.

The potential and importance of beneficial microorganisms, such as PGPR, to promote plant growth and improve health has been widely concerned (Babalola et al. 2010; Shoresh et al. 2010). Consistent with previous results, in our experiments, B3 promoted the growth of rice roots and lateral root development, while F. proliferatum caused the leaf curling and stem morbid elongation, resulting in chlorosis and unhealthy plants. We observed that the disease and growth stress of rice leaves instant-inoculation with B3 were not decreased, while reduced and alleviated in rice leaves pre-inoculation with B3. The significant difference in the colonization of $F$. proliferatum in rice leaves instant-inoculation with B3 and preinoculation with B3 may explain this result. Interestingly, the colonization of B3 in rice root instantinoculation with B3 was significantly lower than that pre-inoculation. In this case, the ability of beneficial microorganisms and pathogen to colonize the host plant determines the outcome of this competition. Due to their superiority in viability or aggressiveness, pathogen first "pre-emptively" on the surface of plants to occupypriority colonization rights and niches, and produce toxins or stimulating metabolites and activate plant defense responses, which may limit the colonization of endophytes (Gonella et al. 2019; Venturi et al. 2012). It has been reported that inoculation with beneficial microorganisms or infection with pathogen limits the colonization of other microorganisms (Martinuz et al. 2012).

Studies have shown that the chloroplast structure was disintegration and chlorophyll synthesis blocked after pathogen invasion, leading to symptoms chlorosis and yellowing of leaves (Zabala et al. 2015). Here we found that the leaves chlorophyll a and carotenoids content in rice pre-inoculation with B3 was remarkably higher than instant-inoculation, and no difference between instant-inoculation with $\mathrm{B} 3$ and $F$. proliferatum infection alone, which indicates that pre-inoculation of B3 decreased the damage of $F$. proliferatum. When tobacco plants are infected with Phytophthora nicotianae, photosynthesis is downregulated accompanied by the complete activation of defense responses and HR responses (Scharte et 
al. 2010). On the contrary, plants with strong photosynthesis accumulate more resistant substances, such as phenolics, which can inhibit the growth of pathogen directly and participate in the formation of physical barriers to plant cells as precursors for lignin synthesis (Farkas et al. 2005). This is consistent with our results. The rice leaves of pre-inoculation with B3 accumulate remarkedly more phenols, which may augment structural barriers of pathogen invasion and improve the rice resistance to $F$. proliferatum. In addition, plants will secrete hydrolase enzymes such as chitinase and $\beta-1,3$-glucanase to degrade the fungal cell wall to destroy the structure of pathogen fungal to limit pathogen colonization on the leaf surface (Cheng et al. 2020). In our study, the hydrolase activities of rice in pre-inoculation with B3 were enhanced after $F$. proliferatum infection, especially the chitinase activity of rice leaves. In summary, these results suggest that pre-inoculation with B3 alleviates the growth stress after $F$. proliferatum infection, stimulates the increase in the synthesis of plant basic defense substances, and enhances the immune response of rice.

Beneficial microorganisms form papillary structures that penetrate the epidermis of plants to create colonization points, accompanied by low-level immune responses of plants, this state enhances the latent defense mechanisms of plants against subsequent challenges from pathogen insect herbivore (Chen et al. 2017). This well-characterized form of beneficial rhizosphere microorganisms- induce resistant mediated by jasmonic acid/ethylene hormone against leaf pathogens or insect is commonly known as induce systemic resistance (ISR) (Pieterse et al. 1996). In our study, Ph. Liquidambaris B3, a beneficial microorganism in the roots, resulted in increased of SA hormone concentration and the upregulated of PATHOGENESIS-RELATED (PR) gene expression. Differently, these characteristics seem to be more similarity with another induced resistance, called systemic acquired resistance (SAR): acquired upon local infect induction by necrotic pathogens and enhance defensive capacity, usually accompanied by an increase of salicylic acid and the coordinate activation of PR genes (Neuenschwander et al. 2003). Although beneficial microbe-induced ISR usually modulates plant defense through SA-independent mechanisms, several PGPRs have been reported can trigger SA-dependent type induced resistance similar to pathogen-induced SAR. For example, the PGPR Pseudomonas fluorescens P3 overexpressing the SA biosynthesis gene cluster of Pseudomonas aeruginosa PAO1 has been shown to induce SA-dependent SAR (MaurhoferM et al. 1998). The beneficial Trichoderma also activates the SA-dependent induction of resistance pathway, thereby enhancing tomato resistance to Fusarium (Jogaiah et al. 2018). There is also a view that plant hormones other than JA/ET can also be used as mediators of ISR (Kesel et al 2021). Pathogenic microorganisms and symbiotic microorganisms may share common strategies in colonizing plants due to the similar MAMPs that can be recognized by plant immune receptors (Wang et al. 2019; Tang et al. 2017). Sun et al. (2020) reported that peanut inoculation with a root endophyte induced activation of salicylic acid-dependent signal transduction to resist soil-borne pathogen Fusarium oxysporum. In addition, genomic analysis showed that Ph. Liquidambaris B3 was closely related to the pathogen Magnaporthe grisea shared a common ancestor of pathogenic fungi, and retained invading nails, which may lead to identification of endophytic fungus B3 and pathogen through similar or common defense pathways. 
The perception of plant to pathogen invasion always accompanied with transient bursts of ROS, the main form is $\mathrm{H}_{2} \mathrm{O}_{2}$, which plays a key role in the plant defense response. However, the excessive accumulation of ROS will disrupt the redox balance of the cells and cause extensive damage to protein, DNA and lipids and thereby affects normal cellular functioning (Mishra et al. 2018; Liu et al. 2020). Preinoculation with root endophyte can effectively suppressed root rot by F. oxysporum by decreasing cell death, pathogen colonization and increasing $\mathrm{SA}$ and $\mathrm{H}_{2} \mathrm{O}_{2}$ level, while were absent in the B3 posttreated roots (Sun et al. 2021). Similarly, we found that rice leaves pre-inoculated with $B 3$ increased the levels of $S A$ and $\mathrm{H}_{2} \mathrm{O}_{2}$ level after infection with $F$. proliferatum. Interestingly, we observed that rice instant inoculation $\mathrm{B} 3 \mathrm{had}$ a strong outbreak of $\mathrm{H}_{2} \mathrm{O}_{2}$ increased significantly in the leaves after $F$. proliferatum infection. The staining of DAB also showed the over accumulation of $\mathrm{H}_{2} \mathrm{O}_{2}$, compared with F. proliferatum infection alone. These results indicated that instant or pre- inoculation with $\mathrm{B} 3$ in rice probable activate different immune pathways after $F$. proliferatum infection and leading to the opposite plant defense outcome, suggesting different roles of B3. In addition, these results implied the differential and adaptive immune response of endophytic fungus Ph. liquidambaris B3 in different plants (such as monocotyledon or dicotyledon) when challenged by specific phytopathogens.

Plants evolved a series of antioxidant enzymes such as superoxide dismutase (SOD) and peroxidase (POD) to control the balance of ROS in order to avoid excessive accumulation of ROS in cells (Peter et al. 2019). In the current study, the SOD enzyme activity in rice leaves instant inoculated with B3 was significantly lower than that pre-inoculated with B3, and the POD enzyme activity as well. These results indicate two possibilities: (1) Rice instant inoculated with B3 inhibited and reduced the antioxidant enzyme activity, resulting in the accumulation of excessive ROS; (2) The limited ROS scavenging capacity of intracellular antioxidant enzymes could not immediately eliminate the massive ROS caused by instant inoculation of B3 and pathogen infection, resulting in an imbalance of ROS in rice leaves. High levels of ROS are considered to be closely associated with the occurrence of lesions and programmed cell death (PCD) (Chai et al. 2015). Here, trypan blue staining and evans blue staining showed that instant inoculation of B3 increased plant cell death in rice leaves while disappeared in rice leaves treated with the ROS scavenger DMTU. The OsRboh family encoding NADPH oxidase, which regulates the synthesis of ROS (Yamauchi et al. 2017). Our results showed that the expression of OsRbohA and OsRbohB genes in rice instant inoculated with B3 was remarkable up-regulated, while the expression of OsPAL2 and OSPR1a, which are involved in the defense-related hormone salicylic acid synthesis pathway, was significantly suppressed. In addition, the programmed cell death genes involved in the biological process of rice were significantly up-regulated in rice instant inoculated B3. Cui et al. (2020) reported that the in the mutant ELLI exhibited serious chloroplast degradation and upregulated expression of chloroplast degradation-related genes, which leads to the decrease in chlorophyll content and excessive ROS accumulation may induce ROS- mediated cell death. In this study, we also found that the chlorophyll content in rice leaves instant inoculated with B3 decreased significantly, and ROS accumulated excessively and caused cell death, while no definite evidence to show the relationship between them. 
Many studies identified that induced resistance (IR) enhance plant defense capabilities rather than immediately active expensive defenses, which usually come at the expense of plant growth. In this stress, plants need to allocate a large amount of energy to activate strong defense responses resulting in energy overdraft that no extra energy to allocate for plants growth (Pieterse et al. 2014). In our research, we found that although instant inoculated with B3 after F. proliferatum infection activates an intense immune response leads to excessive accumulation of ROS and cell death. Obviously, this is an ineffective plant defense response. In addition, necrotrophy plant pathogens such as most Fusarium sp. must absorb nutrients from dead plant tissues and cells, which may accelerate the process of plant death (Cachinero et al. 2010). These results raise a referable suggestion, that is, for certain plant pathogens, the application of beneficial microorganisms may be ineffective and meaningless when the disease appeared or has occurred, and such "belated" management measures may even aggravate the disease in actual agricultural production, which is a choice that outweighed the gain. Commercial chemical fungicides are widely used as common means to control crop diseases (Henkler et al 2011). For example, tebuconazole disturb the formation of cell membranes by inhibiting the sterol demethylation synthesis of pathogenic fungi to control crop disease (Xue et al 2018). However, beneficial microorganisms show significant difference from this strategy of directly targeting the growth, development and reproduction of pathogens. Although some beneficial microorganisms can secrete secondary metabolites to act on plant pathogens, the first step for most beneficial microorganisms to participate in the defense of plant pathogens is to stimulate plant immune response and induce plant resistance rather than directly killing the pathogens (Martinuz et al. 2012; Sharifi et al 2017; Montesinos et al. 2002). Similar to human vaccines, beneficial microorganisms can be considered as plant vaccines. This feature determines that the key role of beneficial microbes in disease control is to prevent and protect plants from pathogens, that is, prevention is more important than treatment.

Our study emphasizes that the application time of beneficial microorganisms may be an important reason for limiting the effect of plant disease prevention and control in agricultural production. Only accurate and pre-relevant treatments before pathogen infection or disease occurrence can effectively prevent the occurrence and spread of diseases. Although our study aimed at a specific plant pathogen, it is indispensable to ensure the efficiency of plant disease control and crop yield on related research on different plant pathogens. In addition, the population density of beneficial microorganisms in the rhizosphere or surface of plants also limit the expression of induced resistance in field crops (Weller et al. 2002). However, the effect of inoculated population density of endophytic fungi $B 3$ on plant disease control is not clear, and further studies are needed. Our research provided new strategies and perspectives for biological control in the large agricultural production environment, that is, considering the precise application factors of biological control agent (BCAs) such inoculation time and inoculation density may be crucial to ensure and improve the effect of farmland crop disease control.

\section{Conclusion}

The main mechanisms of biological control seem to be summarized into two types: (1) direct interaction of microorganisms and (2) stimulated and activated the plant immune system. Our results showed that 
the inoculation time of rhizosphere beneficial microorganisms affects the immune response of plants and leads to the opposite result of disease control. Pre-inoculation of endophytic fungus $P h$. liquidambaris B3 may triggered the SA-dependent defense pathways of plants, induced plant system resistance, enhanced and promoted triggering faster and stronger immune responses upon the subsequent pathogen challenges to suppressed F. proliferatum infection in rice leaves, including increased defense-related enzyme activities and resistance substances accumulation and up-regulated the expression of defense genes. However, instant inoculation Ph. liquidambaris B3 (that is, when pathogen infection or has happened) up-regulated the expression of reactive oxygen synthesis genes, caused excessive burst of ROS and cell death. These results emphasized the significance of the application time of beneficial microorganisms in plant disease control (here it can be considered that the instant inoculation B3 simulated the situation after pathogen infection in the farmland environment).

\section{Declarations}

\section{Compliance with ethical standards}

\section{Conflict of interest}

The authors declare that they have no conflict of interest.

\section{Acknowledgement}

This work was supported by the National Key Research and development program of China (project No. 2017YFD0800705), the Program for Jiangsu Excellent Scientific and Technological Innovation team (17CXTD00014). The authors express their great thanks to anonymous reviewers and editorial staff for their time and attention.

\section{References}

1. Barrio-Duque AD, Samad A, Nybroe O, Antonielli L, Sessitsch A, Compant S (2020) Interaction between endophytic proteobacteria strains and Serendipita indica enhances biocontrol activity against fungal pathogens. Plant Soil 451(1):277-305

2. Babalola $O O$ (2010) Beneficial bacteria of agricultural importance. Biotech Lett 32(11):1559-1570

3. Balint-Kurti P (2019) The plant hypersensitive response: concepts, control and consequences. Molecular Plant Pathology 20(8):1163-1178

4. Berg G (2009) Plant-microbe interactions promoting plant growth and health: perspectives for controlled use of microorganisms in agriculture. Appl Microbiol Biotechnol 84(1):11-18

5. Bindschedler LV, Dewdney J, Blee KA, Stone JM, Asai T, Plotnikov J et al (2006) Peroxidasedependent apoplastic oxidative burst in Arabidopsis required for pathogen resistance. Plant $\mathrm{J}$ 47:851-863 
6. Carrión VJ, Perez-Jaramillo J, Cordovez V, Tracanna V, De Hollander M, Ruiz-Buck D et al (2019) Pathogen-induced activation of disease-suppressive functions in the endophytic root microbiome. Science 366(6465):606-612

7. Chai T, Zhou J, Liu J, Xing D (2015) LSD1 and HY5 antagonistically regulate red light inducedprogrammed cell death in Arabidopsis. Front Plant Sci 6. https://doi.org/10.3389/fpls.2015.00292

8. Chen A, Gu M, Wang S, Chen J, Xu G (2017) Transport properties and regulatory roles of nitrogen in arbuscular mycorrhizal symbiosis. Semin Cell Dev Biol 74:80-88

9. Chen T, Nomura K, Wang X, Sohrabi R, Xu J, Yao L, He SY (2020) A plant genetic network for preventing dysbiosis in the phyllosphere. Nature 580:653-657

10. Cheng T, Yao XZ, Wu CY, Zhang W, He W, Dai CC (2020) Endophytic Bacillus megaterium triggers salicylic acid-dependent resistance and improves the rhizosphere bacterial community to mitigate rice spikelet rot disease. Appl Soil Ecol 156:103710

11. Chen Y, Peng Y, Dai CC, Ju Q (2011) Biodegradation of 4-hydroxybenzoic acid by Phomopsis liquidambaris. Appl Soil Ecol 51:102-110

12. Cachinero JM, A Hervás RM, Jiménez-Díaz, Tena M (2010) Plant defence reactions against fusarium wilt in chickpea induced by incompatible race 0 of Fusarium oxysporum f.sp. ciceris and nonhost isolates of F. oxysporum. Plant Pathol 51(6):765-776

13. Coll NS, Epple P, Dangl JL (2011) Programmed cell death in the plant immune system. Cell death differentiation 18(8):1247-1256

14. Corina Vlot A, Dempsey DA, Klessig DF (2009) Salicylic acid, a multifaceted hormone to combat disease. Annual Review of Phytopathology 47(1):177-206

15. Cui H, Tsuda K, Parker JE (2015) Effector-triggered immunity: From pathogen perception to robust defense. Annu Rev Plant Biol 66:487-511

16. Cui Y, Peng Y, Zhang Q, Xia S, Ruan B, Xu Q et al (2020) Disruption of EARLY LESION LEAF 1, encoding a cytochrome P450 monooxygenase, induces ROS accumulation and cell death in rice. Plant J 105(4):942-956

17. Dangl JL, Jones J (2001) Plant pathogens and integrated defense responses to infection. Nature 411(6839):826-833

18. Das K, Roychoudhury A (2014) Reactive oxygen species (ROS) and response of antioxidants as Rosscavengers during environmental stress in plants. Frontiers in Environmental Science 2(53) https://doi.org/10.3389/fenvs.2014.00053

19. De Bruyne L, H€ofte M, De Vleesschauwer D (2014) Connecting growth and defense: the emerging roles of brassinosteroids and gibberellins in plant innate immunity. Mol Plant 7:943-959

20. Farkas GL, Kiraaly Z (2005) Role of phenolic compounds in the physiology of plant diseases and disease resistance. J Phytopathol 44(2):105-150

21. Finkel OM, Castrillo G, Paredes SH, González IS, Dangl JL (2017) Understanding and exploiting plant beneficial microbes - sciencedirect. Curr Opin Plant Biol 38:155-163 
22. Gonella E, Tedeschi R, Crotti R, Alma E A (2019) Multiple guests in a single host: interactions across symbiotic and phytopathogenic bacteria in phloem-feeding vectors - a review. Entomol Exp Appl 167(3):171-185

23. Han Q, Ma Q, Chen Y, Tian B, Xu L, Bai Y, Chen W, Li X (2020) Variation in rhizosphere microbial communities and its association with the symbiotic efficiency of rhizobia in soybean. The ISME Journal 14(8):1915-1928

24. Hematy K, Cherk C, Somerville S (2009) Host-pathogen warfare at the plant cell wall. Curr Opin Plant Biol 12:406-413

25. Henkler F, Luch A (2011) Adverse health effects of environmental chemical agents through 486

26. non-genotoxic mechanisms. Journal of epidemiology and community health 65(1):1-3

27. Huai B, Yang Q, Qian Y, Qian W, Liu J (2019) Aba-induced sugar transporter tastp6 promotes wheat susceptibility to stripe rust. PLANT PHYSIOLOGY 181(3):1328-1343

28. Hunt MG, Rasmussen S, Newton PCD, Parsons AJ, Newman JA (2005) Nearterm impacts of elevated $\mathrm{CO}_{2}$, nitrogen and fungal endophyte-infection on Lolium perenne L. growth, chemical composition and alkaloid production. Plant Cell Environ 28:1345-1354

29. Hussain B, War AR, Sharma HC (2013) Jasmonic and salicylic acid-induced resistance in sorghum against the stem borer chilo partellus. Phytoparasitica 42(1):99-108

30. Jones JD, Dangl JL (2006) The plant immune system. Nature 444:323-329

31. Jogaiah S, Abdelrahman M, Tran LP, Ito S (2018) Different mechanisms of Trichoderma virensmediated resistance in tomato against Fusarium wilt involve the jasmonic and salicylic acid pathways. Molecular Plant Pathology 19:870-882

32. Kesel JD, Conrath U, Flors V, Luna E, Mageroy M, Mauch-Mani B, Kyndt T (2021) The induced resistance lexicon: do's and don'ts. Trends Plant Sci 26(7):685-691

33. Lee M, Jeon HS, Kim SH, Chung JH, Roppolo D, Lee H, Cho HJ, Tobimatsu Y, Ralph J, Park OK (2019) Lignin-based barrier restricts pathogens to the infection site and confers resistance in plants. The EMBO Journal 38:e101948

34. Liu X, Zhou Q, Guo Z, Liu P, Shen L, Chai N (2020) A self-balancing circuit centered on moosm1 kinase governs adaptive responses to host-derived ROS in Magnaporthe oryzae. eLife 9:1-28

35. Pastor L, Flors R, Mauch-Mani, Ton J (2011) Callose deposition: a multifaceted plant defense response. Mol Plant Microbe Interact 24(2):183-193

36. Lugtenberg B, Kamilova F (2009) Plant-growth-promoting rhizobacteria. Annu Rev Microbiol 63:541556

37. Maurhofer M, Reimmann C, Schmidli-Sacherer P, Heeb SD, D’efago G (1998) Salicylic acid biosynthesis genes expressed in Pseudomonas fluorescens strain P3 improve the induction of systemic resistance in tobacco against tobacco necrosis virus. Phytopathology 88:678-684

38. Martinuz A, Schouten A, Sikora RA (2012) Systemically induced resistance and microbial competitive exclusion: implications on biological control. Phytopathology 102:260-266 
39. Mou Z, Fan W, Dong X (2003) Inducers of plant systemic acquired resistance regulate npr1 function through redox changes. Cell 113(7):935-944

40. Mishra A, Singh SP, Mahfooz S, Singh SP, Bhattacharya A, Mishra N, Nautiyal CS (2018) Endophytemediated modulation of defense-related genes and systemic resistance in Withania somnifera (L.) dunal under Alternaria alternata stress. Appl Environ Microbiol 84(8):02845-02817

41. Morcillo RJL, Singh SK, He DX, An G, Vílchez JI, Tang K, Yuan FT, Sun YX, Zhang HM (2019) Rhizobacterium-derived diacetyl modulates plant immunity in phosphate-dependent manner. The EMBO Journal 39:e102602

42. Montesinos E, Bonaterra A, Badosa E, Francés J, Alemany J, Llorente I, Moragreg C (2002) Plantmicrobe interactions and the new biotechnological methods of plant disease control. Int Microbiol 5(4):169-175

43. Murphy AM, Zhou T, Carr JP (2020) An update on salicylic acid biosynthesis, its induction and potential exploitation by plant viruses. Current Opinion in Virology 42:8-17

44. Mun BG, Lee WH, Kang SM, Lee SU, Lee IJ (2020) ) Streptomyces sp. Ih 4 promotes plant growth and resistance against Sclerotinia sclerotiorum in cucumber via modulation of enzymatic and defense pathways. Plant Soil 448(1-2):87-103

45. Neuenschwander U, Lawton K, Ryals J (2003) Systemic acquired resistance. Springer US. https://doi.org/10.1007/978-1-4613-1213-0_3

46. Park G, Xue C, Li Z, Lam S, Xu JR (2002) Mst12 regulates infectious growth but not appressorium formation in the rice blast fungus magnaporthe grisea. Mol Plant Microbe Interact 15(3):183-192

47. Rodriguez PA, Rothballer M, Chowdhury SP, Nussbaumer T, Falter-Braun P (2019) Systems biology of plant-microbiome interactions. Mol Plant 12(6):804-821

48. Peer R, Niemann GJ, Schippers B (1991) Induced resistance and phytoalexin accumulation in biological control of Fusarium wilt of carnation by Pseudomonas sp. strain WCS417r. Phytopathology 81:728-734

49. Peter BK (2019) The plant hypersensitive response: concepts, control and consequences. Molecular Plant Pathology 20(8):1163-1178

50. Pieterse CMJ, Van Wees SCM, Hoffland E, Van Pelt JA, Van Loon LC (1996) Systemic resistance in Arabidopsis induced by biocontrol bacteria is independent of salicylic acid accumulation and pathogenesis-related gene expression. Plant Cell 8(8):1225-1123

51. Pieterse CMJ, Zamioudis C, Berendsen RL, Weller DM, Van Wees SCM, Bakker PAHM (2014) Induced systemic resistance by beneficial microbes. Annual Review of Phytopathology 52:347-375

52. Rodriguez PA, Rothballer M, Chowdhury SP, Nussbaumer T, Falter-Braun P (2019) Systems biology of plant-microbiome interactions. Mol Plant 12(6):804-821

53. Sahoo RK, Bhardwaj D, Tuteja N (2013) Biofertilizers: a sustainable eco-friendly agricultural approach to crop improvement. Plant Acclimation to Environmental Stress. Springer New York 403432 
54. Scharte J, Schön H, Weis E (2010) Photosynthesis and carbohydrate metabolism in tobacco leaves during an incompatible interaction with Phytophthora nicotianae. Plant Cell Environment 28(11):1421-1435

55. Schreiter S, Sandmann M, Smalla K, Grosch R (2014) Soil type dependent rhizosphere competence and biocontrol of two bacterial inoculant strains and their effects on the rhizosphere microbial community of field-grown lettuce. PLoS One 9(8). https://doi.org/10.1371/journal.pone.0103726

56. Sharifi R, Lee S, Ryu C (2017) Microbe-induced plant volatiles. New Phytol 220(3):484-691

57. Shoresh M, Harman GE, Mastouri F (2010) Induced systemic resistance and plant responses to fungal biocontrol agents. Annual Review of Phytopathology 48:21-43

58. Spoel SH, Dong X (2012) How do plants achieve immunity? Defense without specialized immune cells. Nat Rev Immunol 12:89-100

59. Sun K, Zhang W, Yuan J, Song SL, Wu H, Tang MJ, Xu FJ, Xie XG, Dai CC (2020) Nitrogen fertilizerregulated plant-fungi interaction is related to root invertase-induced hexose generation. FEMS Microbiol Ecol (96):8. https://doi.org/10.1093/femsec/fiaa139

60. Sun K, Xie XG, Lu F, Zhang FM, Zhang W, He W, Dai CC (2021) Peanut preinoculation with a root endophyte induces plant resistance to soil-borne pathogen Fusarium oxysporum via activation of salicylic acid-dependent signaling. Plant Soil 460:297-312

61. Sridevi G, Parameswari C, Sabapathi N, Raghupathy V, Veluthambi K (2008) Combined expression of chitinase and $\beta$-1,3-glucanase genes in indica rice (Oryza sativa L.) enhances resistance against Rhizoctonia solani. Plant Sci 175(3):283-290

62. Tang DZ, Wang GX, Zhou JM (2017) Receptor kinases in plant- pathogen interactions: More than pattern recognition. Plant Cell 29:618-637

63. Venturi V, Silva D (2012) Incoming pathogens team up with harmless 'resident' bacteria. Trends Microbiol 20(4):160-164

64. Vogel C, Bodenhausen N, Gruissem W, Vorholt JA (2016) The Arabidopsis leaf transcriptome reveals distinct but also overlapping responses to colonization by phyllosphere commensals and pathogen infection with impact on plant health. The New Phytologist 212:192-207

65. Walters DR, Jaan R, Havis ND (2013) Controlling crop diseases using induced resistance: challenges for the future. J Exp Bot 64(5):1263-1280

66. Wang E, Schornack S, Marsh J, Gobbato E, Schwessinger B, Eastmond P (2012) A common signaling process that promotes mycorrhizal and oomycete colonization of plants. Curr Biol 22(23):22422246

67. Wang W, Feng B, Zhou JM, Tang DZ (2019) Plant immune signaling: advancing on two frontiers. J Integr Plant Biol 62(1):2-24

68. Wang Y, Dai CC, Zhao YW, Peng Y (2011) Fungal endophyte-induced volatile oil accumulation in Atractylodes lancea plantlets is mediated by nitric oxide, salicylic acid and hydrogen peroxide. Process Biochem 46:730-735 
69. Weidner S, Koller R, Latz E, Kowalchuk G, Bonkowski M, Scheu S, Jousset A (2015) Bacterial diversity amplifies nutrient-based plant- soil feedbacks. Funct Ecol 29(10):1341-1349

70. Weller DM, Raaijmakers JM, McSpadden Gardener BB, Thomashow LS (2002) Microbial populations responsible for specific soil suppressiveness to plant pathogens. Annual Review of Phytopathology 40:309-348

71. Wohlgemuth H, Mittelstrass K, Kschieschan S, Bender J, Weigel HJ, Overmyer K, Kangasjärvi H, Sandermann C (2002) Activation of an oxidative burst is a general feature of sensitive plants exposed to the air pollutant ozone. Plant Cell Environ 25:717-726

72. Xu T, Li Y, Zeng X, Yang X, Yang Y, Yuan S (2017) Isolation and evaluation of endophytic Streptomyces endus osish-2 with potential application for biocontrol of rice blast disease. Journal of the Science of Food Agriculture 56(4):498-503

73. Xue D, Hang Y, Liu C (2018) The fungicidal activity of tebuconazole enantiomers against fusarium graminearum and its selective effect on don production under different conditions. Journal of Agricultural Food Chemistry 66(14):3637-3643

74. Yamauchi T, Yoshioka M, Fukazawa A, Mori H, Nishizawa NK, Tsutsumi N, Yoshioka H, Nakazono M (2017) An NADPH oxidase RBOH functions in rice roots during lysigenous aerenchyma formation under oxygen-deficient conditions. Plant Cell 29(4):775-790

75. Yuan J, Sun K, Deng-Wang MY, Dai CC (2016) The mechanism of ethylene signaling induced by endophytic fungus Gilmaniella sp. al12 mediating sesquiterpenoids biosynthesis in Atractylodes lancea. Front Plant Sci 7(63). https://doi.org/10.3389/fpls.2016.00361

76. Zabala MdeT, Littlejohn G, Jayaraman S, Studholme D, Bailey T, Lawson T (2015) Chloroplasts play a central role in plant defence and are targeted by pathogen effectors. Nature plants 1:15075

77. Zamioudis C, Pieterse CMJ (2012) Modulation of host immunity by beneficial microbes. Mol Plant Microbe Interact 25:139-150

78. Zandi P, Yang JJ, Xia X, Barabasz-Krasny B, Możdżeń M, Puła J, Bloem E, Wang YS, Hussian S, Li Q (2021) Sulphur nutrition and iron plaque formation on roots of rice seedlings and their consequences for immobilisation and uptake of chromium in solution culture. Plant Soil.

https://doi.org/10.1007/s11104-021-04870-8

79. Zhao C, Zhao X, Zhang J, Zou W, Zhang Y, Li L, Liu J (2016) Screening of Bacillus strains from sun vinegar for efficient production of flavonoid and phenol. Indian Journal of Microbiology 56(4):498503

80. Zhu Q, Tang MJ, Yang Y, Sun K, Tian LS, Lu F, Hao AY, Dai CC (2020) Endophytic fungus Phomopsis liquidambaris B3 induces rice resistance to control RSRD caused by Fusarium proliferatum and promote plant growth. J Sci Food Agric 101(10):4059-4075

\section{Figures}


a

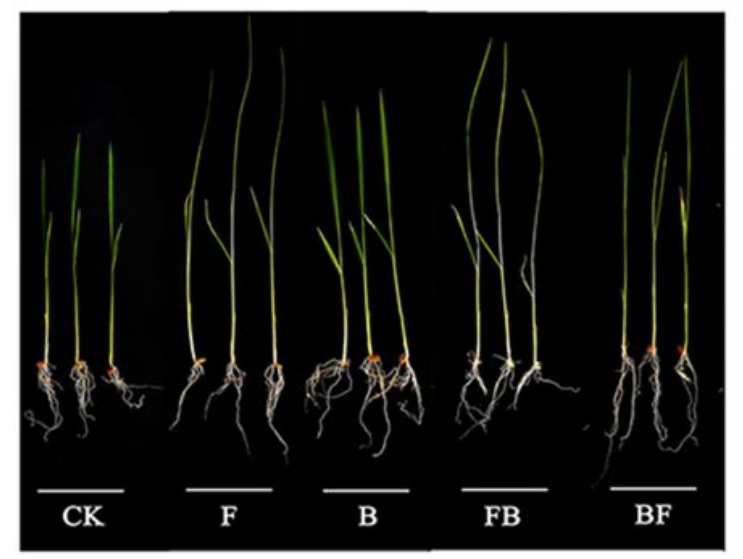

b

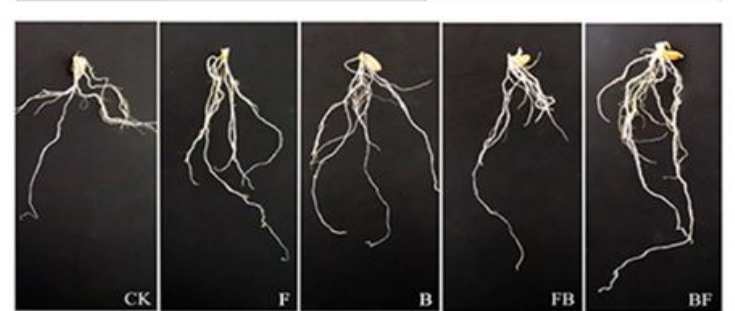

f

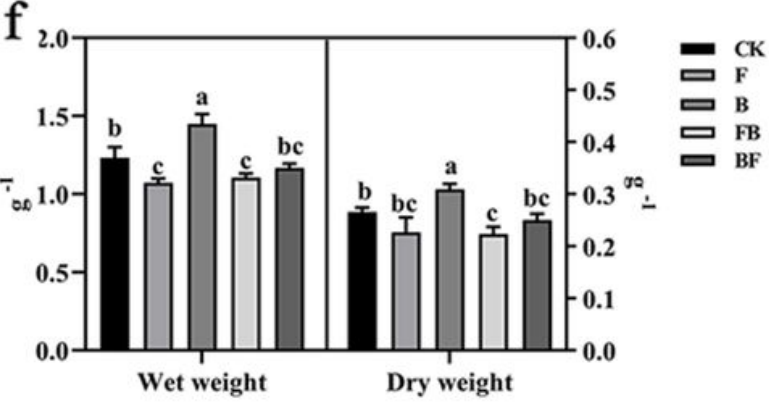

C

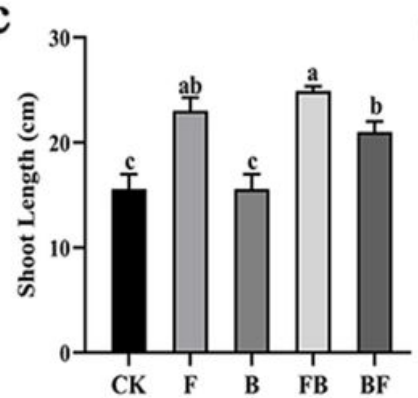

d
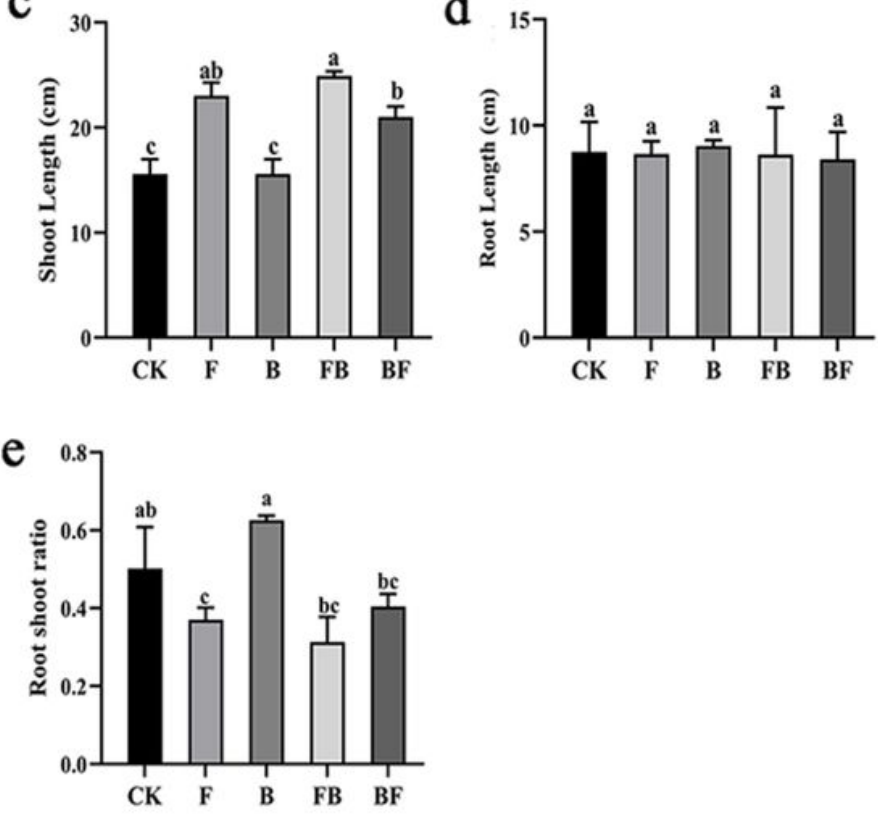

g.

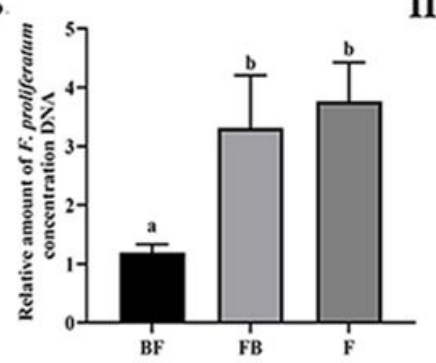

h

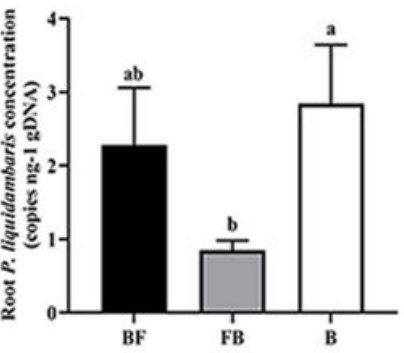

\section{Figure 1}

Rice plants after $14 \mathrm{~d}$ of F. proliferatum infection. (a) Rice plants after F. proliferatum infection. (b) Rice root growth after F. proliferatum infection. (c) Shoot length of rice. (d) Root length of rice. (e) Root shoot ratio of rice. (f) Wet weight and Dry weight of rice. (g) The content of F. proliferatum in rice leaves. (h) The content of P. Liquidambaris in rice roots. Values are the means of three independent replicates $(n=3)$ and standard error (SE). Comparisons between different treatments were considered significant at $p<0.05$ following Tukey's multiple-comparison test. Comparisons between different treatments were considered significant at $p<0.05$ following Tukey's multiple-comparison test. 
a

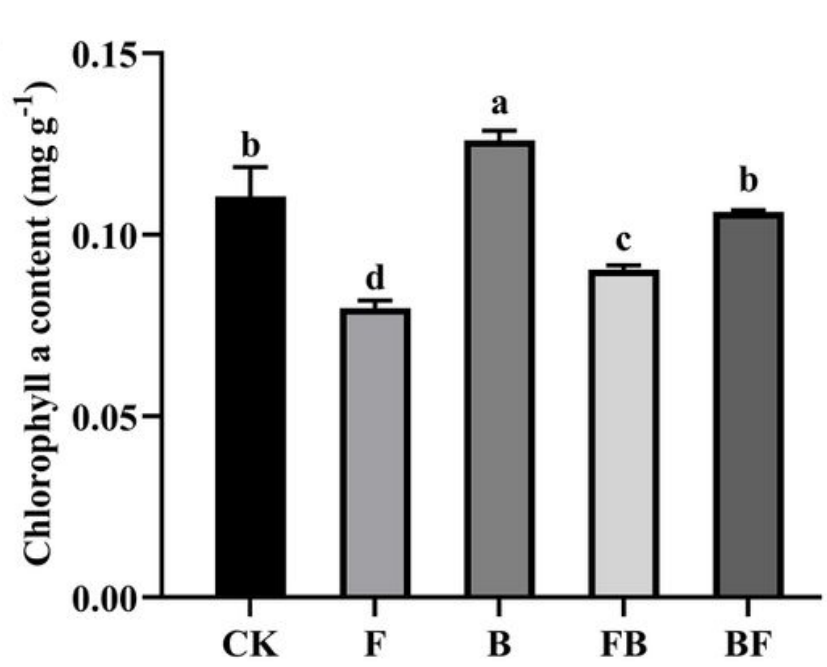

C

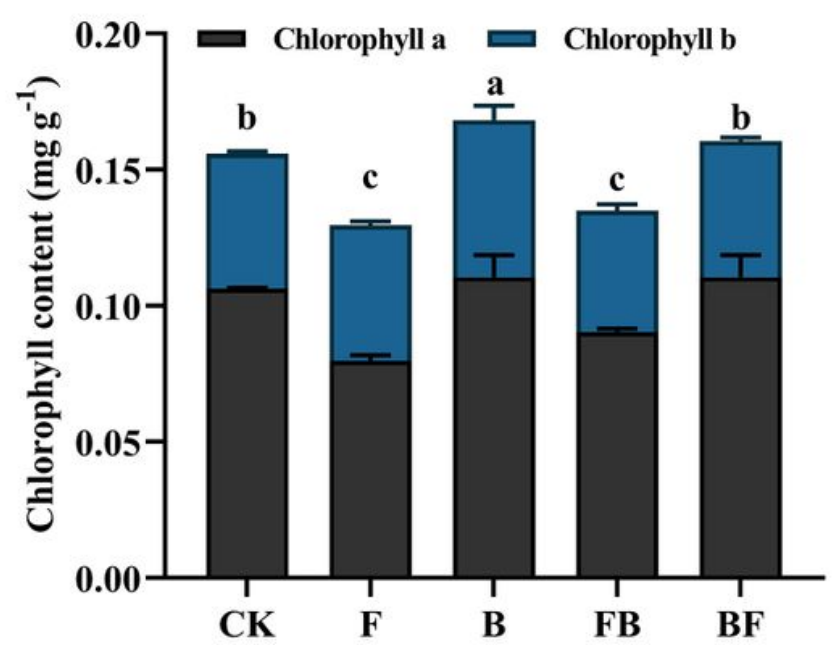

b
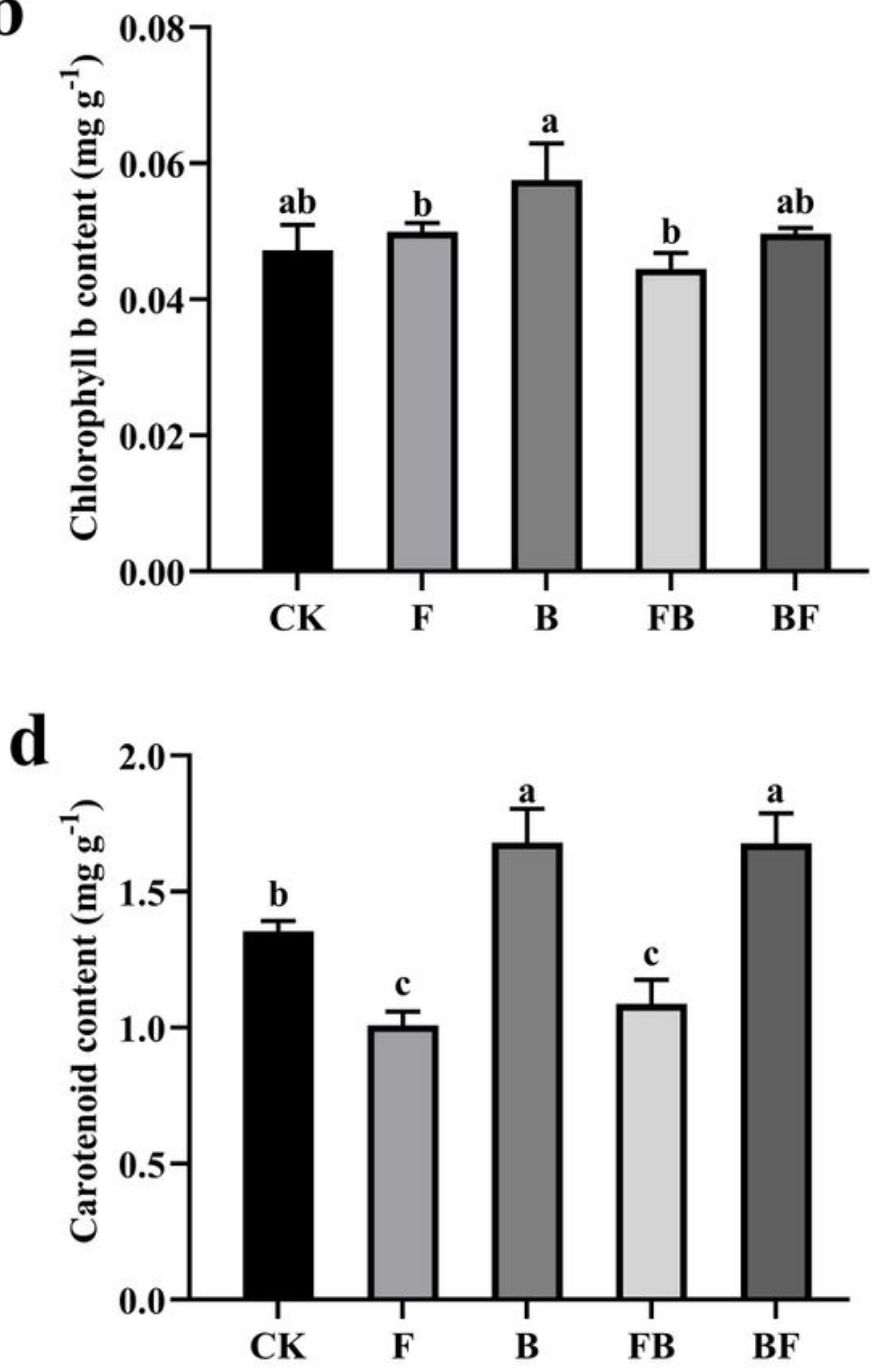

Figure 2

Photosynthesis of rice leaves after $14 \mathrm{~d}$ of F. proliferatum infection. (a) Chlorophyll a content in rice leaves. (b) Chlorophyll b content in rice leaves. (c) Chlorophyll content in rice leaves. (d) Carotenoid content in rice leaves. Values are the means of three independent replicates $(n=3)$ and standard error (SE). Comparisons between different treatments were considered significant at $p<0.05$ following Tukey's multiple-comparison test. Comparisons between different treatments were considered significant at $p<$ 0.05 following Tukey's multiple-comparison test. 
a

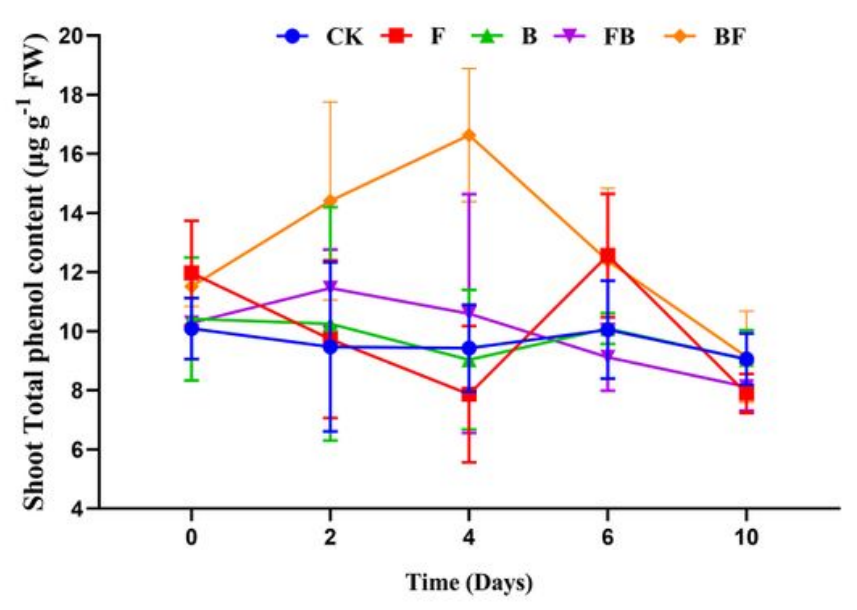

b

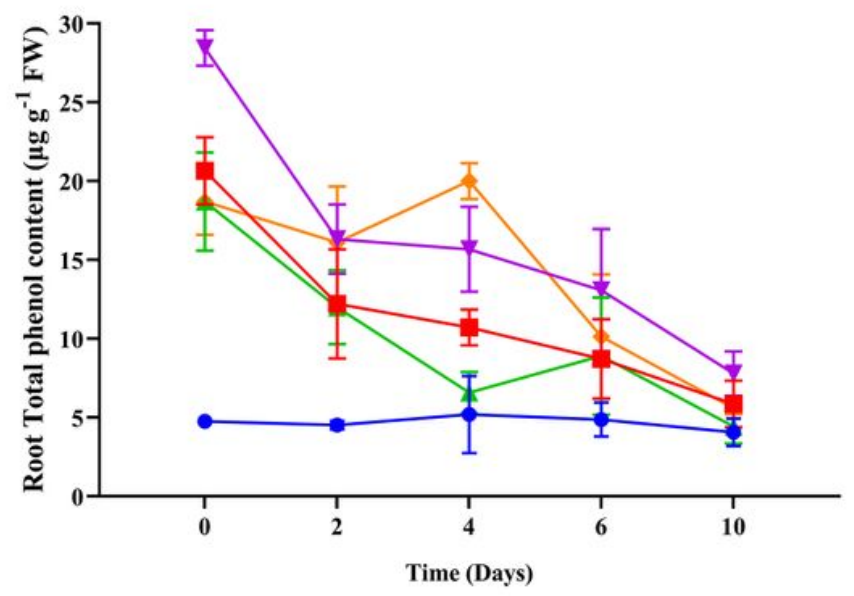

Figure 3

Total phenol content in rice after F. proliferatum infection. (a)Shoot total phenol content in rice. (b) Root total phenol content in rice. Values are the means of three independent replicates $(n=3)$ and standard error (SE). Comparisons between different treatments were considered significant at $p<0.05$ following Tukey's multiple-comparison test. Comparisons between different treatments were considered significant at $p<0.05$ following Tukey's multiple-comparison test. 

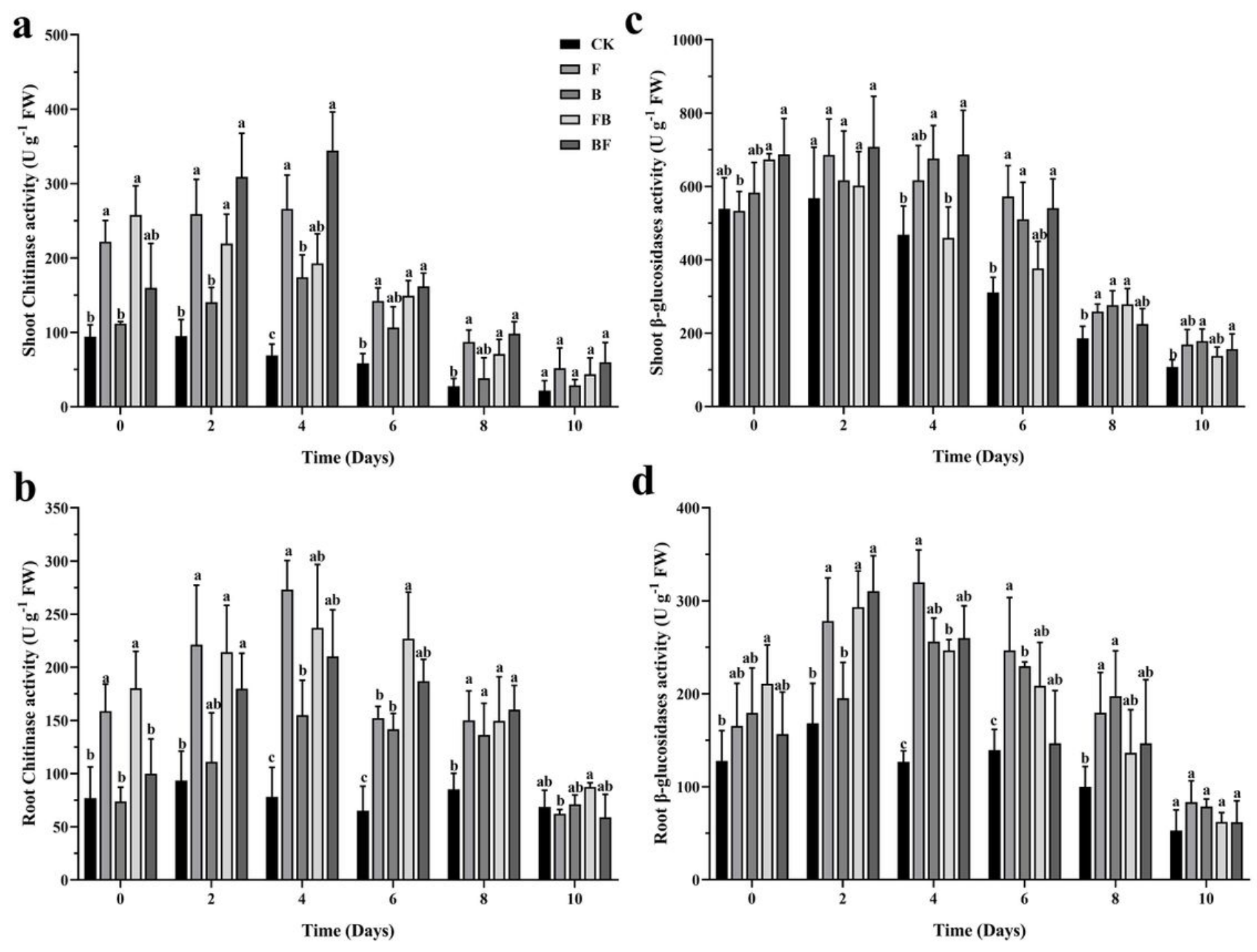

Figure 4

Defense- related enzyme activity in rice after F. proliferatum infection. $(a, b)$ Chitinase enzyme activity in rice shoot and root. (c, d) $\beta$-1,3-glucanase activity in rice shoot and root. Values are the means of three independent replicates $(n=3)$ and standard error (SE). Comparisons between different treatments were considered significant at $p<0.05$ following Tukey's multiple-comparison test. Comparisons between different treatments were considered significant at $p<0.05$ following Tukey's multiple-comparison test. 

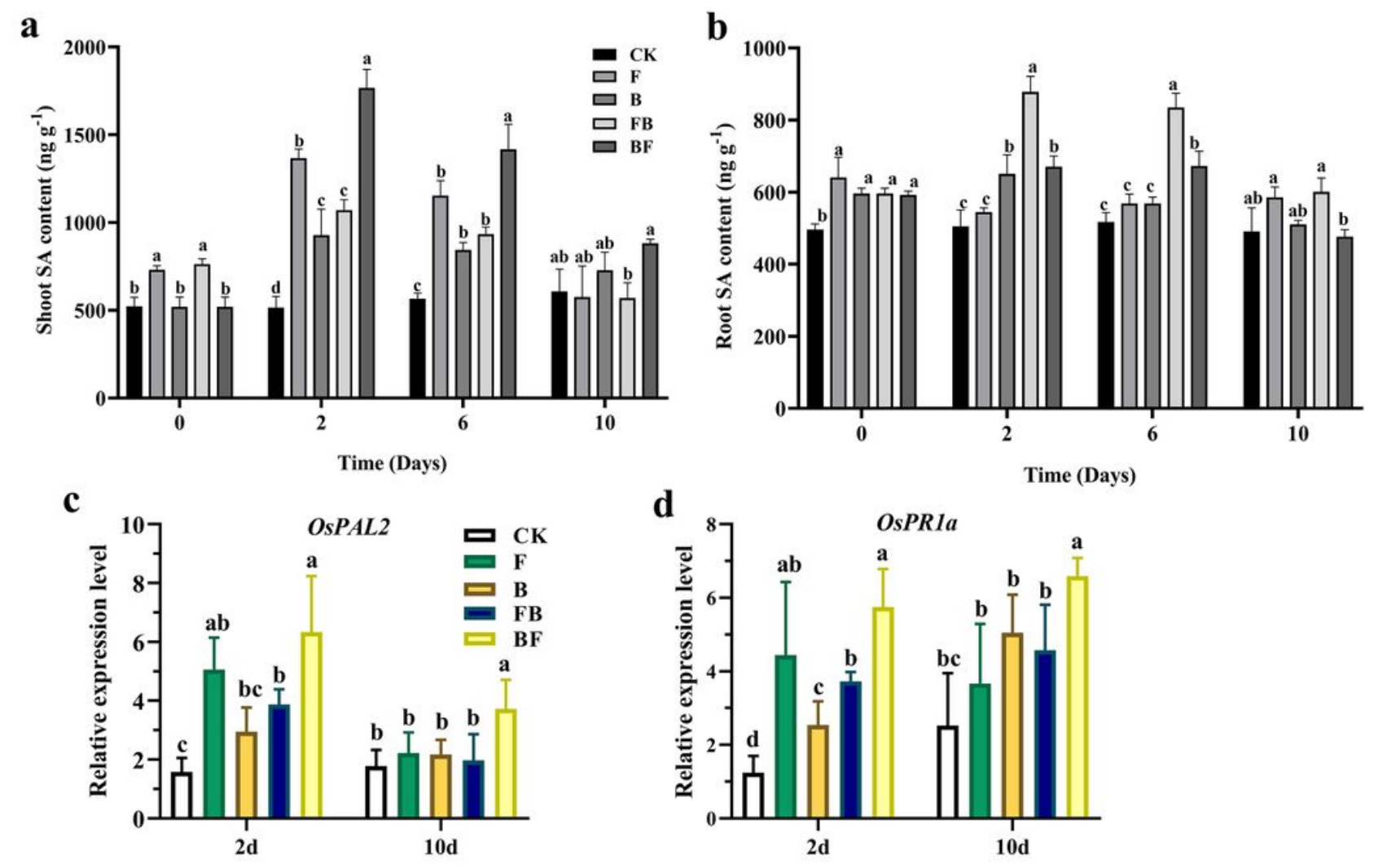

Figure 5

Plant hormone SA content in rice after F. proliferatum infection. (a) SA content in rice shoot. (b) SA content in rice root. Values are the means of three independent replicates $(n=3)$ and standard error (SE). Comparisons between different treatments were considered significant at $p<0.05$ following Tukey's multiple-comparison test. 
a

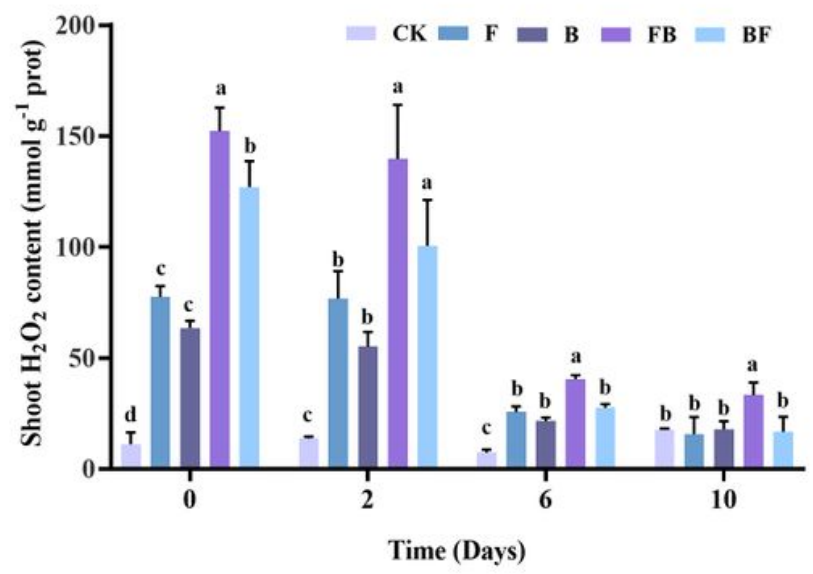

b

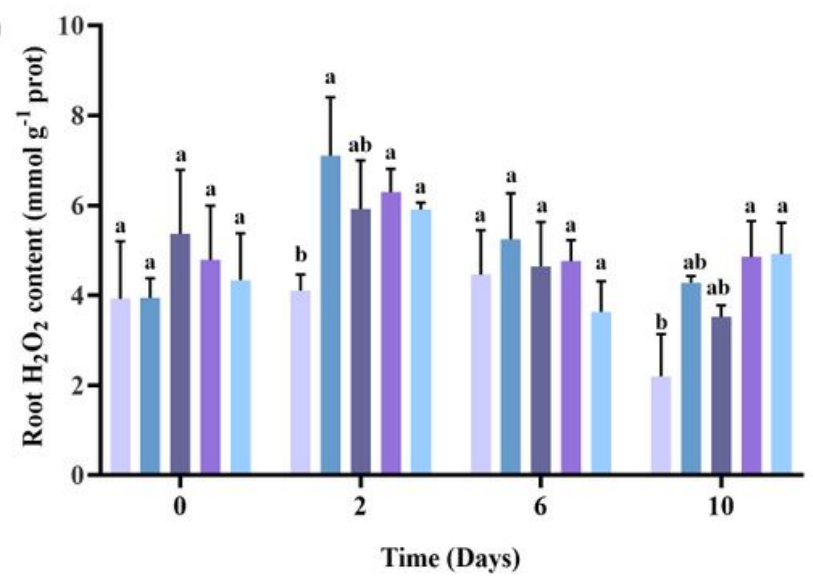

c

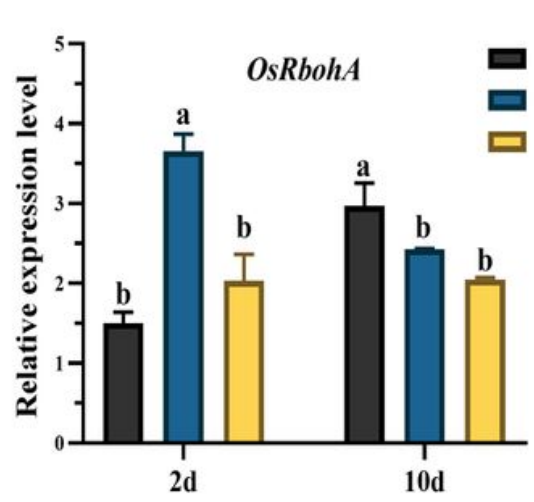

d

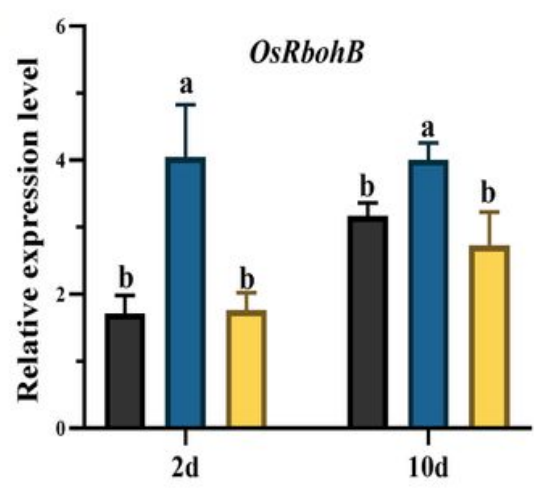

Figure 6

The content of $\mathrm{H} 2 \mathrm{O} 2$ in rice after F. proliferatum infection. (a, b) The content of $\mathrm{H} 2 \mathrm{O} 2$ in rice shoot and $\operatorname{root}(\mathrm{c})$ The transcriptional level of OsRbohA in rice shoot. (d) The transcriptional level of OsRbohB in rice shoot. Values are the means of three independent replicates $(n=3)$ and standard error (SE). Comparisons between different treatments were considered significant at $p<0.05$ following Tukey's multiplecomparison test. 

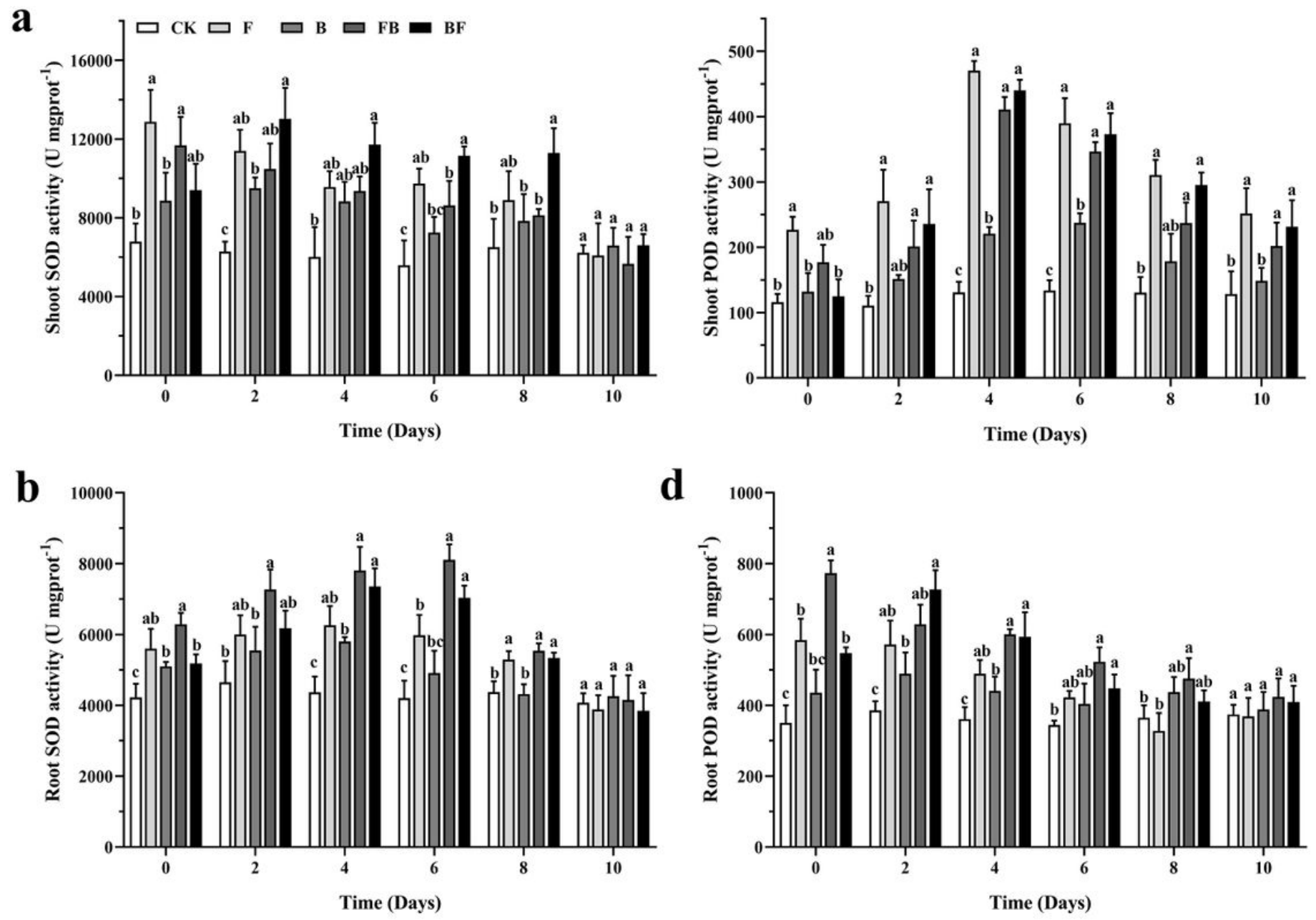

\section{Figure 7}

Reactive oxygen scavenging enzyme activity in rice after F. proliferatum infection. $(a, b)$ SOD enzyme activity in rice shoot and root. (c, d) POD activity in rice shoot and root. Values are the means of three independent replicates $(n=3)$ and standard error (SE). Comparisons between different treatments were considered significant at $p<0.05$ following Tukey's multiple-comparison test. Comparisons between different treatments were considered significant at $p<0.05$ following Tukey's multiple-comparison test. 

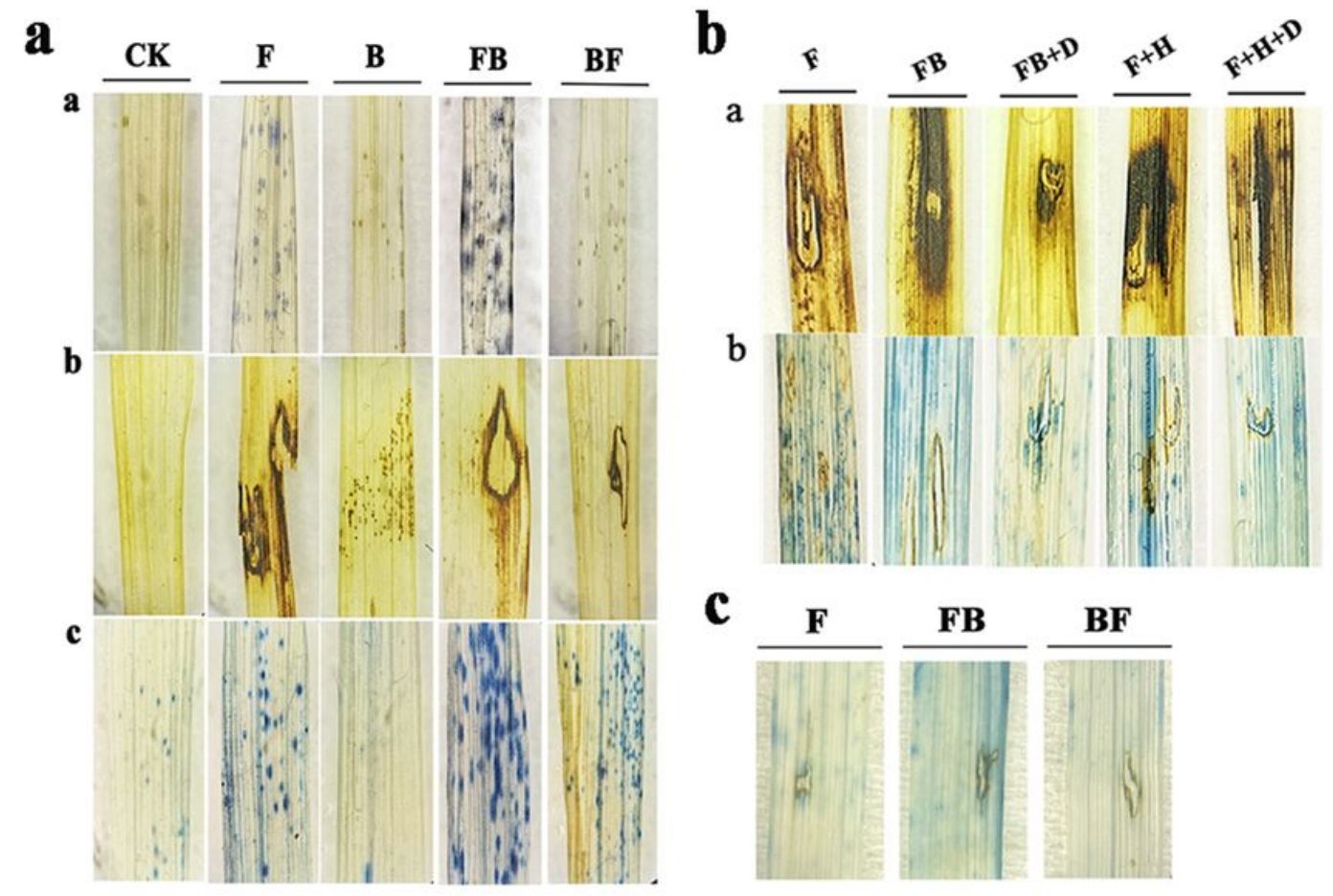

d
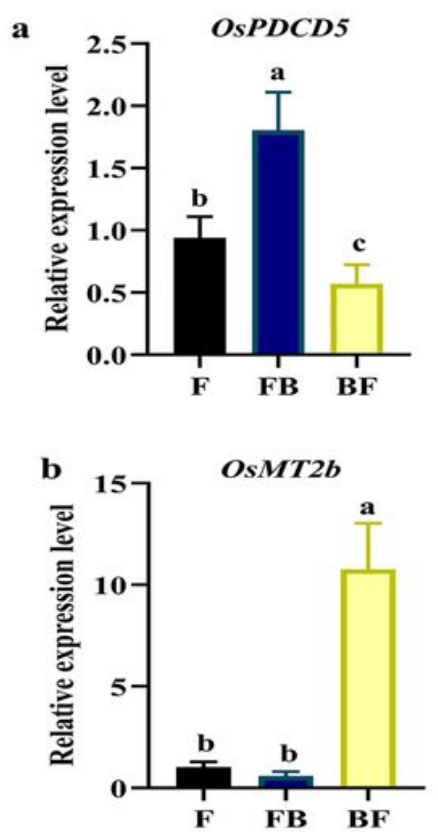

Figure 8

ROS burst and plant death in rice leaves. (a) ROS burst and plant death in rice leaves after $14 \mathrm{~d}$ of $\mathrm{F}$. proliferatum infection. From the top to the bottom are NBT staining, DAB staining and Trypan blue staining. (b) ROS burst and plant death in FB rice leaves after chemical treated. (DAB staining and Trypan blue staining). (c) Plant cell death detect by Evans blue staining. (d) The transcriptional level of OsPDCD5 and OsMT2b in rice shoot.

\section{Supplementary Files}

This is a list of supplementary files associated with this preprint. Click to download.

- Supplementarymaterials.docx 